\title{
Does Child Sponsorship Pay Off In Adulthood? An International Study of Impacts on Income and Wealth
}

\author{
Bruce Wydick ${ }^{\star}$, Paul Glewwe ${ }^{\star *}$, and Laine Rutledge ${ }^{\star \star \star}$ \\ "Wydick, Professor, Department of Economics, University of San Francisco, 2130 Fulton Street, \\ San Francisco, CA 94117-1080 \\ ${ }^{* *}$ Professor, Department of Applied Economics, University of Minnesota, 1994 Buford Ave, St. \\ Paul, MN 55108
}

${ }^{* * *}$ Rutledge, doctoral student, Department of Economics, University of Washington, 319 Savery Hall, Seattle, WA 98195-3330

\begin{abstract}
We estimate the impact of international child sponsorship on adult income and wealth of formerly sponsored children using data on 10,144 individuals in six countries. To identify causal effects, we utilize an age-eligibility rule followed from 1980 to 1992 that limited sponsorship to children 12 years old or younger when the program was introduced in a village, allowing comparisons of sponsored children with older siblings who were slightly too old to be sponsored. Estimations indicate that international child sponsorship increased monthly income by $\$ 13-17$ over an untreated baseline of $\$ 75$, principally from inducing higher future labor market participation. We find evidence for positive impacts on dwelling quality in adulthood, and modest evidence of impacts on ownership of consumer durables in adulthood, limited to increased ownership of mobile phones. Finally, our results also show modest effects of child sponsorship on childbearing in adulthood.
\end{abstract}

\section{Keywords}

Child sponsorship; developing countries; income; wealth; childbearing

\section{Introduction}

Millions of households in wealthy countries support non-profit organizations whose aim is to alleviate poverty in the developing world. But only recently has a growing body of research in development economics begun to rigorously evaluate the impact of these programs on their intended beneficiaries. ${ }^{1}$ International child sponsorship is one of the most popular approaches taken by ordinary households in wealthy countries to help impoverished children overseas. We estimate that there are 9.14 million sponsored children in the world

Correspondence to: Paul Glewwe.

${ }^{1}$ See for example Cristia et al. (2012) evaluating the One Laptop Per Child Program, Rawlins et al. (2014) on the nutritional impacts of dairy cows and meat goats donated via the Heifer Project, and the analysis of Blattman et al. (2014) on cash transfers. 
today, the vast majority of whom are sponsored by individuals and families in wealthy countries. ${ }^{2}$ Donors typically contribute $\$ 25-40$ per month to sponsor a child. In many cases child sponsorship organizations use these funds to provide school uniforms, tuition, nutritious meals, and programming that directly benefits sponsored children. Other types of sponsorship programs pool funds to invest in programming and infrastructure that benefits children in the community more broadly. ${ }^{3}$

For many individuals, child sponsorship represents their most direct contact with the poor in developing countries. Donors are drawn to child sponsorship because of the personalization of the relationship between sponsor and child. But whether child sponsorship actually benefits sponsored children has remained an open question. In Wydick, Glewwe, and Rutledge (2013), a companion paper to this research, we find international child sponsorship to have a statistically significant and positive effect on educational outcomes in all six survey countries (Bolivia, Guatemala, Kenya, Uganda, India, and the Philippines). Sponsorship during childhood increased the probability of secondary school completion by $12-18$ percentage points over a $44.5 \%$ baseline, and increased completed years of schooling by 1.03-1.45 years. Sponsorship also increased adult white-collar employment by 6.5 percentage points over an $18.5 \%$ baseline as well as the probability of being a community leader.

Previous research has studied the impacts of various programs on children's persistence in school in developing countries. Examples include Drèze and Kingdon (2001) and Kremer and Vermeersch (2004), who find positive impacts of school meal programs on school attendance in India and Kenya, respectively. In a randomized trial, Evans, Kremer and Ngatia (2008) find a nearly $40 \%$ reduction in absenteeism from the random provision of free school uniforms, while Kremer, Miguel, and Thornton (2009) estimate that a merit scholarship program for girls boosted attendance by 5 percentage points. Aside from our research, the only other investigation related to ascertaining the impacts of international child sponsorship is Kremer, Moulin, and Namunyu (2003). In this paper the authors assess the impact of a Dutch child-sponsorship program, finding that even a relatively low-cost program focused on the provision of school uniforms and textbooks to each child caused sponsored children to advance a third of a grade farther in schooling completion.

In this paper we present results for the impacts of child sponsorship on the adult income 4 and wealth of children sponsored through one of the leading international child sponsorship organizations. An understanding of these impacts is important for the millions of individuals in wealthy countries involved in international child sponsorship, individuals who are likely to view their contributions as an investment in these overseas children that yields tangible

\footnotetext{
${ }^{2}$ We estimate this figure based on comprehensive internet search across multiple languages for sponsorship programs. For details on how the 9.12 million figure was compiled, see Wydick, Glewwe, and Rutledge (2013).

${ }^{3}$ Of the top ten child sponsorship organizations, a more direct child-centered approach is taken by Compassion International, ChildFund, Children International, CFCA, and Bornefonden. The community-centered approach is favored by World Vision, Plan International, Kindernothilfe, Save the Children, and SOS Children's Villages.

${ }^{4}$ Our study examines changes in labor income, which includes wages paid by an employer, income earned by an entrepreneur from a small enterprise, or income from farming. We do not study income earned from capital holdings, as these were deemed to be insignificant for the great majority of the households in our sample. In our study, the terms "labor income" and "wages" have a similar meaning but are not exactly the same; we use the term "wages" as conditional on working status and "labor income" in contexts that are unconditional on working status, e.g. labor income increases when one enters the workforce and begins to earn a wage.
} 
economic returns in the future, when they are adults. But it is also important for governments in countries implementing similar programs that work directly with impoverished children, helping them to understand whether direct investments in child development are financially sustainable by virtue of the positive impacts on the future incomes of beneficiaries. Thus we ask the question: Does international child sponsorship pay off for children in adulthood?

\section{Methodology}

Fieldwork for our six-country study took place from 2008 to 2010. We obtained initial enrollment lists from village projects that were rolled out from 1980 to 1992 by Compassion International, the world's third largest sponsorship organization, which currently sponsors over 1.3 million children in 26 countries. Compassion's child sponsorship program is a very intensive intervention in the lives of impoverished children. Children typically begin sponsorship at age 4-6 and continue into their mid-teens. Many sponsored children attend retreats together with program staff that focus on the nurture of their spiritual and moral values as well as their aspirations. Since even in a typical week children typically spend about 8-10 hours per week after school and on Saturdays participating in the program, and because the average duration of sponsorship is 9.3 years, this means that during the course of their childhood, on average sponsored children spend slightly more than 4,000 hours participating in Compassion programming. Average years of participation by country is given in Table 1.

Across the countries in which it is implemented, the Compassion program contains many similar elements. In each country Compassion uses funding to provide tuition fees for children, several nutritious meals per week, basic healthcare, school uniforms, and an afterschool tutoring program. The tutoring program not only helps sponsored children with homework and gives them additional academic instruction, but emphasizes spiritual and character formation and the development of schooling and vocational aspirations and selfesteem. Note that vocational training was not included in any of these six countries.

The program has changed slightly since the time of the study and varies somewhat between countries. In the past, Compassion worked in tandem with local schools (which is true of our data from Guatemala and the Philippines) but more recently has operated through local church-affiliated tutoring centers. We study the impacts from children involved in the program in India and Bolivia when small cash transfers were given to parents of participating children, but not in other countries. Other than these differences the program across countries is highly standardized.

Through the use of local enumerators, we were able to locate $93.5 \%$ of the families of these formerly sponsored children, who by the time of the survey were aged 17 to 43 . Our field personnel were unaffiliated with Compassion, in order to reduce bias in the responses of our subjects. We administered our survey first-hand to households of formerly sponsored children, a random sample of non-participating households in 19 program villages, and a random sample of households in 13 neighboring, non-program villages. The survey questionnaire was administered to family members (typically parents or adult siblings) 
present at the time of the survey, and data were obtained on all adult siblings in the household cohort, including the non-sponsored siblings of sponsored children. We also administered the survey to 50-75 randomly selected households with children in a similar cohort age that did not participate in the program in program villages, as well as 50-75 randomly selected households with children in a similar cohort age in nearby non-program villages.

Overall, our data contain information on educational and vocational outcomes, monthly labor income, consumer good ownership, and dwelling quality on 1,860 formerly sponsored children, 3,704 of their unsponsored siblings, 2,136 individuals of a similar age from nonparticipating families in villages where the Compassion program operated, and 2,444 individuals from similar, nearby villages without the Compassion program.

There are several empirical challenges to estimating the program's causal effects on future income and wealth. First, there may be non-random selection of households with eligible children into the program. Second, since a limited number of children per household were eligible for sponsorship (ranging from one in the African countries to three in the Latin American countries), intra-household selection of children for sponsorship may not be random. Third, there may be spillover effects from sponsored children onto their siblings, or onto other children in the village, which complicates the estimation. Lastly, when estimating impacts on future labor income, it is useful to distinguish between impacts on employment and impacts on wages, conditional on employment.

To identify causal effects of child sponsorship, we use a program age-eligibility requirement, which stipulated that only children 12 and under could enter the program in any year, including the program's first year in a village. Figure 1 shows the program's strong adherence to this rule. Because a child's age at the time of program rollout in his or her village is independent of adult life outcomes, except via its impact on program participation, we can use the age-eligibility rule as an instrumental variable that allows one to account (and test) for non-random intra-household selection of children for sponsorship. To address possible endogenous household selection into the program, we present estimates with household fixed effects, which control for unobserved differences in parenting behavior and household environments. ${ }^{5}$ Implicitly, this compares life outcomes of children who were ageeligible for sponsorship with their siblings who were too old for sponsorship when the program arrived in their village.

The regression estimates allow for the possibility of spillovers. Dummy variables are included for: (a) Sponsored children, who were 12 or younger when the program started in their villages (denoted by $T=1$ ); (b) Program participants' siblings who were 12 or younger when the program began in their villages and, while eligible, were not selected for sponsorship (denoted $D_{1}^{\leq 12}=1$ ); (c) Program participants' siblings age 13-16 when the program arrived in their villages, and thus were ineligible $\left(D_{1}^{13-16}=1\right)$; (d) Individuals in non-Compassion households in program villages who were 12 or younger at program

\footnotetext{
${ }^{5}$ We found that program staff usually selected households for participation, and then parents chose which children to be sponsored.
} 
introduction ( $D_{2}^{\leq 12}=1$ ); (e) Individuals in non-Compassion households in program villages age 13-16 at program introduction $\left(D_{2}^{13-16}=1\right.$ ); (f) Individuals 12 or younger in non-Compassion villages when the program started in a neighboring village $\left(D_{3}^{\leq 12}=1\right.$ ); and $(\mathrm{g})$ Individuals 13-16 in non-Compassion villages when the program began in a neighboring village ( $D_{3}^{13-16}=1$ ). Individuals 17 or older in non-program villages are the omitted category.

The household fixed-effects equation for child $i$ in household $j$ is

$$
\begin{aligned}
& y_{i j}=\alpha_{1} D_{1 i j}^{\leq 12}+\alpha_{2} D_{1 i j}^{13-16}+\tau\left(D_{1 i j}^{\leq 12} * T_{i}\right)+\beta_{1} D_{2 i j}^{\leq 12} \\
& +\beta_{2} D_{2 i j}^{13-16}+\gamma_{1} D_{3 i j}^{\leq 12}+\gamma_{2} D_{3 i j}^{13-16}+\boldsymbol{X}_{i j} \boldsymbol{\varphi}+\theta_{j}+\varepsilon_{i j}
\end{aligned}
$$

where $y_{i j}$ measures labor income or wealth, $\boldsymbol{X}_{i j}$ is a vector of controls that include age, gender, birth order and oldest child, and $\theta_{j}$ is a household fixed effect. Assuming that spillovers: (a) occur only within villages; and (b) affect age-eligible, but not age-ineligible, siblings of sponsored children, then $\left[\alpha_{1}-\alpha_{2}\right]-\left[\gamma_{1}-\gamma_{2}\right]$ captures spillovers from sponsored children onto non-sponsored siblings age 12 and younger and $\left[\beta_{1}-\beta_{2}\right]-\left[\gamma_{1}-\gamma_{2}\right]$ captures spillovers onto age-eligible children in non-Compassion households in program villages. ${ }^{6}$

To address possibly endogenous selection of age-eligible children within families we use instrumental variable estimation. The oldest age-eligible sibling was sponsored most often, followed by the second-oldest age-eligible sibling, third oldest, etc., so the instruments are interaction terms between three age-at-program-rollout categories (4 years and under, 5-8, 9-12) and dummy variables for oldest age-eligible sibling, second-oldest age-eligible sibling, and younger age-eligible siblings, yielding a vector of nine instruments. ${ }^{7}$ In the first stage, the probability of sponsorship, $\widehat{T}_{i}$, is estimated using these instruments and the vector of controls; $\widehat{T}_{i}$ replaces the treatment variable $\left(T_{i}\right)$ in (1) in a second-stage regression.

Estimating the impact of sponsorship on monthly wages involves another challenge: wages are unobserved for the $61 \%$ in the sample who were not working. This suggests the use of Heckman (1979) estimation for the wage impact regressions, which uses a probit employment equation to generate an Inverse Mills ratio for each observation in a secondstage wage regression. Given certain assumptions, this removes bias from the censored wage variable (the dependent variable in second equation).

Using this approach allows us to decompose overall labor income impacts of child sponsorship into the impact from formerly sponsored children obtaining employment and

\footnotetext{
${ }^{6}$ Spillovers onto non-sponsored siblings may reflect extra income available from sponsorship, role model effects, and parental reallocation of assistance to non-sponsored children.

${ }^{7}$ An identical set of instruments are used in Wydick et al. (2013).
} 
the impact on wages conditional on employment. These two effects are seen by differentiating the expected average wage, $E(w)$, where

$$
E(w)=\Phi\left(z^{\prime} \gamma\right) \boldsymbol{\square} w\left(\boldsymbol{x}^{\prime} \boldsymbol{\beta}\right)
$$

and $\Phi\left(z^{\prime} \gamma\right)$ is the probability that an individual works and earns a wage, based on characteristics $z$, and $w\left(\boldsymbol{x}^{\prime} \boldsymbol{\beta}\right)$ is the individual's wage, conditional on working, based on characteristics $\boldsymbol{x}$. To estimate $\boldsymbol{\beta}$ without assuming arbitrary functional forms, $z$ should have one or more variables that are excluded from $x$; we use the individual's number of children, which strongly affects the probability of employment but should have relatively little effect on wages. ${ }^{8}$ Both $x$ and $z$ include the sponsorship (treatment) variable, T. Differentiating (2) with respect to $T$, and setting variables to their means, gives

$$
\frac{\partial E(w)}{\partial T}=\frac{\partial \Phi\left(z^{\prime} \gamma\right)}{\partial T} \mathbf{\square} w\left(\overline{\boldsymbol{x}}^{\prime} \boldsymbol{\beta}\right)+\frac{\partial w}{\partial T} \mathbf{\square} \Phi\left(\bar{z}^{\prime} \boldsymbol{\gamma}\right)
$$

The first term gives the impact of sponsorship on income from its employment effect; the second is the impact of sponsorship on wages, conditional on employment.

Both terms in (3) are obtained using Heckman's method; $\Phi\left(z^{\prime} \gamma\right)$ is estimated using a probit specification, and $w\left(\boldsymbol{x}^{\prime} \boldsymbol{\beta}\right)$ is essentially equation (1). To calculate the standard errors of the employment effect (the first term in (3)), a bootstrapping procedure is used; estimates of $\frac{\partial \Phi\left(z^{\prime} \gamma\right)}{\partial T}$ and of the average wage are obtained from a random draw (with replacement) from the sample. These two estimates are multiplied for each bootstrap iteration and (householdlevel clustered) standard errors are obtained from 500 bootstrapped replications. Similarly, the impact of sponsorship on wages (the second term in (3)) is the product of the estimate of $\frac{\partial w}{\partial T}$ and mean labor market participation; for each bootstrapped sample (with replacement), the entire estimation procedure, which combines estimates of the probit equation with those of the wage equation, is implemented, and 500 bootstrap replications are used to obtain standard errors.

For all 10,144 individuals in the study, interviewers attempted to obtain current labor income, which in our use of the term covers fixed wages paid by an employer, itinerate wages, estimated monthly income from a small business, or income from farming; all of this we refer to as wages. We did not collect data on non-labor income (such as returns on assets), which were infrequently realized among the low-income households in our sample.

\footnotetext{
8 It is possible that there are unobserved characteristics that reduce individuals' wages and also influence their fertility (e.g. tastes for children, or lower labor productivity, which reduces the opportunity cost of raising children). This could cause the error term in the wage equation to be correlated with the number of children, invalidating number of children as an identifying variable in the selection equation. This seems unlikely for men, but it may occur for women. To check the robustness of our results, we tried two alternative approaches. First, we used "electrified household" as the excluded variable. Such households are more likely to be near labor markets, so that individuals in them are more likely to be employed, but it is unlikely that this variable directly affects wages. Second, we used no exclusion restriction and thus relied on the assumed normality of the probit error term to identify our selection term. These two approaches yielded very similar results and thus suggest that our findings are robust to different identifying assumptions.
} 
For $83 \%$ of those who were reported to be working for any wage at all, they or their family members reported the wages of the individual. For the remaining $17 \%$ no one could provide a wage figure, but for nearly all of these individuals, family members knew their completed schooling and current occupation. Using data on education, occupation, gender and age (and country fixed effects), labor income was imputed for all individuals in the sample. Two estimates of labor income impacts from sponsorship were thus implemented; one drops the $17 \%$ of the sample without wage data, and the other imputes labor income values to all individuals in the sample, including those with observed wages. ${ }^{9}$ A hybrid in which we impute labor income only for missing observations yields estimates very similar to the latter estimates. Assuming that any imputation errors are independent of the explanatory variables in equation (1), estimates using imputed values are consistent and unbiased (Wooldridge 2010, p.77). To carry out estimations by country and gender we use the imputed labor income, which yield slightly lower (yet more precise) impact estimates than do our directly reported wage data.

To examine the impact of child sponsorship on adult wealth, we examine two broad categories: indicators of current dwelling quality, and current ownership of common consumer durable goods and land. The dwelling quality measures include the presence of an indoor toilet, electricity, walls constructed of sturdy materials (e.g. wood or concrete, rather than mud or sticks), high quality roofs (constructed from tile, concrete, or high-quality wood, rather than thatch, leaves, or low-quality corrugated iron), and high quality floors (concrete, wood, or tile, rather than dirt floors or floors made from other natural materials). For the second wealth proxy, information was collected on ownership of mobile phones, bicycles, motorcycles, automobiles, and land.

To address issues of over-testing and joint-testing of related hypotheses, two types of indices were created. The first simply weights each of the five variables within a category equally; OLS and GMM IV estimations are then carried out on these simple indices. Secondly, for each of these two categories of variables we created an Anderson (2008) summary index. This index is created by de-meaning each of the dependent variables in the respective category $j$ ( $j \in$ dwelling, consumer goods), then weighting each observation by the sum of its row entries across the inverted variance-covariance matrix of the dependent variables in the group. Specifically, each observation $i$ in group $j$ receives a weight (index score) of $\bar{s}_{i j}=\left(1^{\prime} \Sigma^{-1} 1\right)^{-1}\left(1^{\prime} \Sigma^{-1} y_{i j}\right)$, where $\mathbf{1}$ is a $m \times 1$ column vector of $1^{\prime} \mathrm{s}, \Sigma^{-1}$ is the $m \times m$ inverted covariance matrix, and $y_{i j}$ is the $m \times 1$ vector of outcomes for individual $i$. Relative to the simple index, the Anderson Index gives more weight to dependent variables within the grouping that are least correlated with other variables, and hence embody the greatest degree of unique information.

\section{Results}

Table 2 provides summary statistics for the data. Monthly labor income is $\$ 16.67$ higher among those who were sponsored as children $(p<0.01)$. This mainly reflects a higher

\footnotetext{
${ }^{9}$ The few individuals whose imputed wages are less than or equal to zero are assigned non-working status.
} 
employment rate (54.5\% to $47.9 \%)$ among formerly sponsored individuals $(p<0.01)$. This is evident in Figure 2; conditional on positive labor income, $(\log )$ income is only slightly higher conditional on positive income, but formerly sponsored individuals show many more positive labor income observations. ${ }^{10}$ Figure 3 illustrates the program's impact in a discontinuity diagram; non-parametric estimation shows that labor income is somewhat higher for individuals in untreated (relative to treated) households among those over age 12 when the program began. However, among those 12 or younger when the program rolled out, income is clearly higher in treated households.

\section{A) Impact on Income}

The impacts of child sponsorship on adult labor income by current age are best seen visually. Figure 4 presents non-parametric estimations of the labor market income trajectories of sponsored (upper line) and unsponsored (lower line) individuals; the impact of sponsorship appears to increase over time (bandwidth $=1$, Epanechnikov kernel). While differences in income are small in the twenties and early thirties, they grow substantially from the mid-thirties to the mid-forties, beyond which our data no longer contain observations of older formerly sponsored individuals.

Heckman estimates of income impacts are provided in Table 3 in columns (1) through (12). The first row of Table 3 presents the marginal impacts of child sponsorship on the probability of working. Column (1) gives estimates without household fixed effects and omits missing income observations, column (2) adds household fixed effects, column (3) uses household fixed effects with imputed labor income (and thus includes observations with missing income data), and columns (4), (5), and (6) provide bootstrapped IV-Heckman estimates that are analogous to the estimates in columns (1), (2) and (3). These estimates are from instrumental variable (IV) estimations in which we regress treatment on our vector of instruments and controls in the first stage and then carry out the Heckman estimation in the second stage, bootstrapping clustered standard errors at the household level for the entire process with 500 replications. The first three columns yield estimated marginal effects of $0.096,0.079,0.068$, for the first-stage (probit) estimations. The second three columns yield estimates of $0.116,0.191$, and 0.186 of the marginal effect of the program on employ-ment. All of the former are significant at $p<0.01$, and the latter at $p<0.05$ and $p<0.10$. While the IV estimates are higher than the estimates in columns (1) - (3), Hausman tests cannot reject the null hypothesis that the standard probit estimate is consistent (the lowest $p$-value is $0.136)$.

The second row of Table 3 provides estimates of $\frac{\partial \Phi\left(z^{\prime} \gamma\right)}{\partial T} \mathbf{-} w\left(\overline{\boldsymbol{x}}^{\prime} \boldsymbol{\beta}\right)$ in (3), the increased income from sponsorship via greater employment. These impacts range from $\$ 12.81$ per month in column (3) to $\$ 38.00$ in column (5). Because we cannot reject the consistency of the standard probit estimates (Hausman test $t=1.49$ ), we emphasize the average impact in columns (1) to (3), which is $\$ 15.23$.

\footnotetext{
${ }^{10}$ To show the density of incomes equal to zero, we specify log income as $\log ($ income +1$)$.
} 
The third row provides second-stage (Heckman) estimates of $\frac{\partial w}{\partial T}$, the impact of sponsorship on wages conditional on employment. ${ }^{11}$ Only the $\$ 6.06$ estimate in column (3) is significant $(p<0.05)$; although two of the three IV-Heckman estimates are much larger, they are very imprecise. Thus it is only over the whole sample (including observations with missing income data) that there is evidence that sponsorship raises incomes conditional upon employment, and when the income impacts in the third row are combined with the probability of employment in the fourth row, $\frac{\partial w}{\partial T} \Phi\left(\bar{z}^{\prime} \gamma\right)$, all estimates are insignificant except for the $\$ 2.64$ estimate ( $p<0.10$ ) in column (3), although again two of the three IV point estimates are considerably larger. Overall, these estimates are consistent with the density functions in Figure 2-the main impact of child sponsorship on income is primarily via increased employment, rather than via increased wages among those already employed.

Columns (7) through (12) in Table 3 show impacts on income due to the increased probability of employment from child sponsorship, replicating the estimate in column (3) for each country. Impacts are highest in India $(\$ 37.61, p<0.01)$, Guatemala $(\$ 27.63, p<0.05)$, and the Philippines $(\$ 17.01, p<0.10)$. And although estimates are positive in every country, they are lower and statistically insignificant in Bolivia (\$8.19), Uganda (\$7.19) and Kenya (\$1.61). ${ }^{12}$ Joint tests for differences across continents indicate significantly lower impacts in Africa than in Asia and Latin America, likely due to comparatively low economic opportunity in these two African countries. This is true even though educational impacts in our companion paper were found to be much stronger in the African countries; this could reflect low returns to education in rural areas of Africa.

In Table 4 we disaggregate our Heckman estimations by gender, and find that the monthly labor income effects from the increased probability of employment are nearly identical in the (first-stage) standard probit estimations (\$12.60 for men, $\$ 12.75$ for women, both $p<$ 0.01). (These correspond to our estimates in column (3) of Table 3.) IV estimates for both are larger, but insigni-ficant. There is a positive impact on wages conditional on employment for men $(\$ 6.74, p<0.01)$, but this effect is zero for women. IV estimates of the marginal effect on men's wages are very large, $\$ 33.15$ and $\$ 53.08$, but imprecisely measured. All effects for the impact on the marginal wage for women are small and insignificant. Thus sponsorship yields an increase in girls' future labor income of $\$ 12.75$, resulting solely from greater labor market participation. But the total impact from sponsorship on boys' future labor income is \$19.34-\$12.60 from higher labor market participation and \$6.74 from higher wages conditional upon labor market participation.

\footnotetext{
${ }^{11}$ The log of labor income is typically used in such regressions, but for decomposition of income effects between the Heckman equation of new entrants into the labor force and the marginal income increases conditional on employment it is more convenient to use levels rather than logs. We checked our results using log income, and they are similar, but this specification becomes very cumbersome analytically and yields little benefit.

${ }^{12}$ Other estimation models yield similar estimates. For example, Ordinary Least Squares (OLS) estimates for the full sample, including those who are not working, and over a variety of specifications, yield significant $(p<0.01)$ estimates ranging from $\$ 16.60$ to $\$ 19.05$. While these OLS estimates combine both employment selection and marginal wage effects, they may be biased because they omit the Inverse Mills ratio, which is included in the Heckman estimation as a right-hand-side regressor. Tobit estimates, which are not preferred because they assume the impacts of the explanatory variables to be the same for the selection and marginal wage effects, yield significant $(p<0.01)$ estimates between $\$ 12.53$ and $\$ 24.51$.
} 
We test for income spillovers onto unsponsored siblings and other children of eligible age within program villages using a joint test of the significance of the linear combinations $\left[\alpha_{1}-\alpha_{2}\right]-\left[\gamma_{1}-\gamma_{2}\right]$ and $\left[\beta_{1}-\beta_{2}\right]-\left[\gamma_{1}-\gamma_{2}\right]$ from (1), but find no evidence of either positive or negative spillover effects in either case ( $p=0.987,0.195$, respectively). Thus we conclude that the benefits of international sponsorship on adult income appear to be limited to the sponsored child.

Figure 5 shows that the impacts on income appear to be smallest among both the least educated and most educated mothers of sponsored children. The largest difference in income between sponsored and non-sponsored children occurs among children of mothers with a primary school education, which is perhaps enough education to offer complementary support to the sponsorship program but not so much that the counterfactual levels of education for children would be high even without sponsorship.

Because most of our impact on income is on the extensive margin (labor market participation) rather than the intensive margin (higher wages), one possibility is that child sponsorship simply encouraged individuals on the margin of labor market participation to move into the labor market. Perhaps the sponsorship program merely raised aspirations for labor market activity rather than genuinely increasing the returns to labor market participation. In this case, the income gains we show here might be only slightly higher than the opportunity cost from work that generates no income such as raising children or subsistence farming.

One way to test whether the income gains from child sponsorship truly increased income or simply substituted income for non-wage opportunity costs of similar value is to estimate the increase in labor market value of sponsorship via its impact on greater schooling completion. In this sense we estimate the individual terms of

$$
\frac{\partial E(w)}{\partial T}=\left[\frac{\partial \Phi\left(z^{\prime} \gamma\right)}{\partial s} \mathbf{m} w\left(\overline{\boldsymbol{x}}^{\prime} \boldsymbol{\beta}\right)+\frac{\partial w}{\partial s} \mathbf{\mathbf { }} \Phi\left(\bar{z}^{\prime} \boldsymbol{\gamma}\right)\right] \frac{\partial s}{\partial T},
$$

where $s$ is years of schooling (more precisely, highest grade attained). Equation (4) is similar to equation (3) except that it measures program impacts on expected wages via the impact of the program on years of completed schooling.

Schooling exhibits significant impacts on labor market participation and the number of children an individual has as an adult. Table 5 shows that each additional year of schooling increases labor market participation by 2.3 percentage points ( 3.2 for women and 1.4 for men). Each additional year of schooling also reduces the number of children (as shown in negative binomial estimations) in columns (4) - (6) by -0.094 children for women and -0.054 for men.

To check whether the program truly increased the financial returns to labor market participation via its impact on schooling we present results from a three-stage procedure in Table 6. In this table we jointly estimate the impact of child sponsorship on schooling (essentially replicating the results in our companion paper) through both OLS and GMM IV 
estimation. The second stage estimates a Heckman wage equation on the non-treated individuals in our sample as a function of total years of education and covariates, in which we obtain an estimate of the monthly income gains from an added year of schooling on the non-treated. In the third stage, we multiply the impact coefficients from the first and second stages by the expected monthly wage, i.e. (sponsorship program impact on schooling) $\times$ (schooling impact on labor market participation) $\times$ (mean monthly labor market wage), to obtain the mean impact of child sponsorship on wages via its impact on schooling and the added value that additional years of schooling yield in the labor market, bootstrapping the entire process with 500 replications. These estimates of the impact of the sponsorship program via the effects of education on labor market participation are given in the middle set of estimates in Table 6, and they show an increase in monthly wages for men between $\$ 3.54$ and $\$ 6.56$; the estimates for women lie between $\$ 3.83$ and $\$ 6.21$.

The third row of estimations repeats this exercise for the income impact of the program via the higher wages that the added schooling from the program yields conditional upon employment, i.e. (sponsorship program impact on schooling) $\times$ (schooling impact on marginal wage, conditional on employment) $\times$ (probability of employment). Estimates here range from $\$ 2.36$ to $\$ 3.92$ for men and from $\$ 4.11$ to $\$ 8.37$ for women. The bottom row of the table shows the total income impacts that accrue to sponsored children simply via added education, $\$ 8.04$ to $\$ 10.48$ per month overall, a little lower for men and a little higher for women, thus representing perhaps $2 / 3$ of the impact of the program. Notably, however, these estimates indicate a higher impact for women on the marginal wage conditional on employment than is actually realized in the program. This may be because young women who finish the program show high rates of entry into the labor market, but choose to undertake relatively low-paid positions commensurate with the human service perspective of the program rather than a focus on higher adult incomes, where this message may have taken root more deeply among formerly sponsored women than among formerly sponsored men.

In many instances the decision to enter the labor force is commensurate with other demographic decisions regarding, for example, marriage and childbearing. Figure 6 shows kernel densities of the number of children in the families of formerly sponsored and unsponsored individuals, now adults; the diagram indicate smaller families in adulthood among the formerly sponsored. Although Figure 7 does not appear to show substantial differences in marriage rates over age by sponsorship status for either gender, Table 7 presents modest evidence that sponsorship may slightly reduce the probability of marriage. Whereas in other estimations spillover effects to siblings were found to be insignificant, and so were omitted from our regression tables, here we find evidence of significant spillovers and therefore present results that account for spillover effects onto (younger) siblings. We find that sponsorship causes a roughly 3 percentage point reduction in the probability of marriage at the time of the survey $(p<0.10)$ with effects reasonably uniform across age groups, perhaps having a slightly larger impact on marriage from age 17 to 21 , although this is measured with noise.

In the negative binomial estimations in columns (4) to (6) of Table 7 we see sponsorship yielding a reduction in family size. This table presents negative binomial estimation coefficients, but these magnitudes translate to marginal effects (accounting for spillovers) of 
0.25 fewer children overall, and 0.64 fewer children for older sponsored children age 40-45 at the time of the survey, with lower point estimates for the younger adults. The impacts on childbearing are likely greater on older individuals simply because birth rates were much higher when these individuals were sponsored back in the early 1980s, and so the impact of greater labor force entry has a stronger effect on birth rates. This can be seen in Figure 8, for example, where birth rates are only slightly lower for the formerly sponsored, but then fall considerably among the older cohort. We do not present impacts by gender; they are virtually identical for men and women.

The increase in income from child sponsorship occurs through different career choices of formerly sponsored men and women. Table 8 presents multinomial logit estimates of the impacts of sponsorship on vocational trajectories, separately by gender. Sponsorship of boys leads them in adulthood into two main types of jobs: K-12 teachers and employees in lowerskill technology jobs, such as work in call centers, with some evidence of an increase in blue-collar employment. Formerly sponsored men are roughly $64 \%$ more likely to be teachers in adulthood relative to the counterfactual and are about $44 \%$ more likely to have a semi-skilled technology job or work in a call center. Sponsorship of girls makes them 50\% less likely to be involved in agriculture as adults, 55\% more likely to have a clerical job, $60 \%$ more likely to work in finance or for a large corporation, $148 \%$ more likely to have a semi-skilled technology job (starting from a very low baseline), and 93\% more likely to be a nurse or health professional.

\section{B) Wealth Impacts}

Finally, we consider the impact of child sponsorship on indicators of wealth in adulthood. Results show that individuals who were sponsored as children live in better houses as adults. Both the simple index and the Anderson index indicate significant impacts of sponsorship on adult dwelling quality. Specifically, OLS (linear probability model) household fixed-effect estimates in Table 9 indicate that sponsorship increases the probability that a home has electricity by 2.9 percentage points, raises the probability of having improved walls by 2.5 percentage points, and increases having improved floors by 1.9 percentage points. GMM-IV estimates are smaller and insignificant for specific improvements, but larger and significant for both dwelling indices.

Does child sponsorship increase consumer durable ownership in adulthood? The only asset with a statistically significant effect is the probability of owning a mobile phone, an increase of 5.4 percentage points in the OLS estimate and 18.3 percentage points in the IV estimate (baseline of 76.8\%). We find no evidence that sponsorship increased ownership of bicycles, motorcycles, vehicles, or land; the IV coefficients on both consumer good summary indices are insignificant.

Tests for household and village level spillovers (not shown) find no significant effects on aggregated dwelling indicators ( $p=0.237$ and $p=0.523$, respectively) or consumer durables ( $p=0.333$ and $p=0.536$ ). Although our research on educational impacts provides evidence for spillovers onto younger siblings, particularly in secondary school completion (Wydick, Glewwe, and Rutledge, 2013), we find no evidence of income or wealth spillovers in our data. 
Tables 10 and 11 disaggregate wealth impact estimations by gender. Not surprisingly, impacts on dwelling quality appear to be higher for formerly sponsored men than for women. OLS estimates for men are positive on every dwelling category-indoor toilet, electrification of the household, improved walls, improved roof, and improved floor-and statistically significant for every category except improved walls. Both the simple dwelling index and the Anderson dwelling index are also strongly significant. However, IV estimates for men are all insignificant. OLS estimates for women indicate that sponsorship appears to affect only the probability of living in a home with electricity, and even this is not significant for the IV estimates. These differences in effects by gender presumably reflect the larger overall impact of sponsorship on the incomes of formerly sponsored men, and they may also reflect that a husband's income has a stronger influence on the type of dwelling in adulthood.

Impacts on consumer durables are virtually identical between formerly sponsored men and women, where estimations indicate a strong and significant impact on cell phone ownership for both genders, but no effect on ownership of a bicycle, motorcycle, car, or land.

Another measure of wealth in adulthood relates to where an individual resides as an adult. Does a grown adult remain in her parents' home, in a rented home, or in an owned home? Typically living in a home apart from parents is desirable after a certain age, especially for married couples, but this is not always economically feasible. Baseline values among the untreated show $46.8 \%$ living in the parents' home, $23.8 \%$ living in a rented home, and 29.4 living in a home owned by the individual or jointly owned with a spouse. Table 12 shows multinomial logit estimations indicating that formerly sponsored individuals are much less likely to remain living in their parents' home (the base category). There is some indication that women are more likely to live in an owned home, but marginal effects are insignificant. Instead of living in their parents' home as adults at the time of the survey, sponsored individuals are 4.8 percentage points more likely to live in a home rented themselves, about two percentage point higher for men than for women.

\section{Conclusion}

International child sponsorship is a leading form of individual contact and financial assistance between ordinary people in developed countries and the poor in developing countries, yet little has been known about the impact of these programs on the economic outcomes in adulthood of sponsored children. Our more conservative Heckman estimates from a six-country study of 10,144 individuals show that child sponsorship is responsible for increases in monthly income of about $\$ 13-17$ over an unconditional baseline of $\$ 75$, or an increase of 17.3-22.9\%. This effect of child sponsorship on future labor income is due principally to sponsored children entering the labor market as adults who would not have done so otherwise, particularly for women. We find that men realize an added $\$ 6.74$ of monthly income from higher wages conditional upon employment, but that estimations on the impact on wages of women cannot reject a null hypothesis of zero. ${ }^{13}$

\footnotetext{
13 As pointed out by a referee, income increases due to increased labor market participation do not account for the implicit cost of reduced leisure time, and since at the margin those two uses of time should be approximately equal the net benefit of child sponsorship via increased labor market participation may be close to zero. However, this ignores the fact that sponsorship can have a variety of
} 
Given that the cost of sponsorship to sponsors was $\$ 28$ per month during the time in the 1980s and 1990s when the individuals in our study were sponsored, and that the average length of sponsorship was 9.3 years, a monthly income increase of \$13-17 over an average lifetime of work implies a modest financial rate of return to child sponsorship of 3.7-5.0\%.

Our estimations of impacts on wealth in adulthood find significant impacts on adult dwelling quality from child sponsorship on proxies for adult wealth, where we find that sponsored children-especially males-are more likely as adults to live in better housing (homes with electricity, and with roof and floor made of superior construction materials). Formerly sponsored men are more likely to live in homes with indoor plumbing. Impacts on adult consumer good ownership, however, are more modest and appear to be limited to substantially greater ownership of mobile phones among both formerly sponsored men and women. We also present (modest) evidence suggesting that sponsored children have fewer children in adulthood, along with much stronger evidence that both formerly sponsored men and women are less likely to live with their parents in adulthood.

What about child sponsorship, in particular Compassion's approach to child sponsorship, could be responsible for these significant effects on income and wealth in adulthood? In related research using a separate sample of currently sponsored children we explore the hypothesis that child sponsorship may improve adult incomes not merely through relieving external constraints that improve schooling access, nutrition, and health, but through addressing internal constraints related to imparting a greater level of hopefulness about the future and instilling greater aspirations for schooling and adult vocation. Using data on currently sponsored children, we find in Glewwe, Ross, and Wydick (2014) a causal link between child sponsorship and elevated educational and vocational aspirations among children in Kenya, and higher levels of happiness, self-efficacy, and hopefulness based on a quantitative analysis of children's self-portrait drawings in Indonesia. Although it is yet impossible to definitively identify these increased aspirations as a causal channel to the positive impact from sponsorship on income and wealth we find in this study, what is clear from our three pieces of research on child sponsorship is that child sponsorship increases aspirations and that child sponsorship also improves adult economic outcomes. We present a diagram in Figure 9 of what appears to us to be the causal channel for the effects we observe from child sponsorship on income and wealth in adulthood.

Most conditional and unconditional cash transfer programs, and many - if not most educational interventions, do not seek to directly address internal constraints of children, which are also related to the fostering of non-cognitive (socio-emotional) skills. Our findings on the impacts of child sponsorship suggest that this may constitute a missed opportunity. Taken together, our results suggest that development programs that relieve tangible external constraints, while simultaneously addressing the internal constraints faced by the poor, may realize stronger impacts than programs that address external constraints alone, thus

non-economic effects that make leisure time more valuable, such as improved health and overall greater psychological well-being. While we cannot estimate those effects with our data, they are likely to be positive, and so even if all of the increased income is due solely to increased labor force participation the net benefit of the program is unlikely to be zero. In addition, some of our estimates in Tables 3, 4 and 6 find positive impacts on wages from sponsorship, and these can serve as a lower bound of the "net" impact of sponsorship on income. 
providing a basis for experimenting with new programs that embody these joint characteristics and for important future research.

\section{Acknowledgments}

We would like to thank Wess Stafford, Joel Vanderhart, Scott Todd, Alistair Sim, Herbert Turyatunga, Jose-Ernesto Mazariegos, Ester Battz, Noel Pabiona, Rowena Campos, Sofia Florance, Catherine Mbotela, Sam Wambugu, Boris Zegarra, Marcela Bakir and other local Compassion staff and enumerators in Bolivia, Guatemala, India, Kenya, the Philippines and Uganda for logistical help and support in carrying out our field research. Thanks to graduate students Joanna Chu, Ben Bottorff, Jennifer Meredith, Phillip Ross and Herman Ramirez for outstanding work in the field. We also appreciate support and helpful comments from Christian Ahlin, Michael Anderson, Jesse AnttilaHughes, Chris Barrett, Jere Behrman, Michael Carter, Alessandra Cassar, Pascaline Dupas, Giacomo De Giorgi, Alain de Janvry, Fred Finan, Pauline Grosjean, Phil Keefer, David Levine, Jeremy Magruder, Craig McIntosh, David McKenzie, Ted Miguel, Douglas Miller, Jeff Nugent, Jon Robinson, Elizabeth Sadoulet, John Strauss, and seminar participants at the University of California at Berkeley, Stanford University, the World Bank, the University of Southern California, the University of California at Davis, the Georgia Institute of Technology, the 2010 and 2011 Pacific Conferences for Development Economics, the Behavior and the Escape from Persistent Poverty (IBEPP) conference at Cornell University. Finally, we thank the editor, Andrew Foster, and three anonymous referees for very helpful comments. We are grateful to BASIS/USAID for substantial funding for this project, to two generous South Korean donors, and to the University of San Francisco's graduate program in International and Development Economics.

\section{References}

Anderson, Michael. Multiple Inference and Gender Differences in the Effects of Early Intervention: A Reevaluation of the Abecedarian, Perry Preschool, and Early Training Projects. Journal of the American Statistical Association. 2008; 103(484):1481-95.

Blattman, Christopher, Fiala, Nathan, Martinez, Sebastian. Generating Skilled Self-Employment in Developing Countries: Experimental Evidence from Uganda. Quarterly Journal of Economics. 2014; 129(2):697-752.

Cristia, Julian, Ibrraran, Pablo, Cueto, Santiago, Santiago, Ana, Severin, Eugenio. IZA working paper No 6104. Bonn, Germany: 2012. Technology and Child Development: Evidence from the One Laptop per Child Program.

Drèze, Jean, Kingdon, Geeta. School participation in rural India. Review of Development Economics. 2001; 5(1):1-24.

Evans, David, Kremer, Michael, Ngatia, Mũthoni. The Impact of Distributing School Uniforms on Children's Education in Kenya. World Bank working paper. 2008

Kremer, Michael, Miguel, Edward, Thornton, Rebecca. Incentives to Learn. Review of Economics and Statistics. 2009; 91(3):437-456.

Kremer, Michael, Vermeersch, Christel. School Meals, Educational Attainment, and School Competition: Evidence from a Randomized Evaluation. World Bank Policy Research Paper no 3523. 2004

Kremer, Michael, Moulin, Sylvie, Namunyu, Robert. Working paper no 10. Poverty Action Lab; Cambridge, MA: 2003. Decentralization: A Cautionary Tale.

Rawlins, Rosemary, Pimkina, Svetlana, Barrett, Christopher, Pederson, Sarah, Wydick, Bruce. Got Milk? The Impact of Heifer International's Livestock Donation Programs in Rwanda. Food Policy. 2014; 44(2):202-13.

Wooldridge, Jeffrey. Econometric Analysis of Cross Section and Panel Data. Cambridge, MA: MIT Press; 2010.

Wydick, Bruce, Glewwe, Paul, Rutledge, Laine. Does Child Sponsorship Work? A Six-Country Study of Impacts on Adult Life Outcomes. Journal of Political Economy. 2013; 121(2):393-436. 

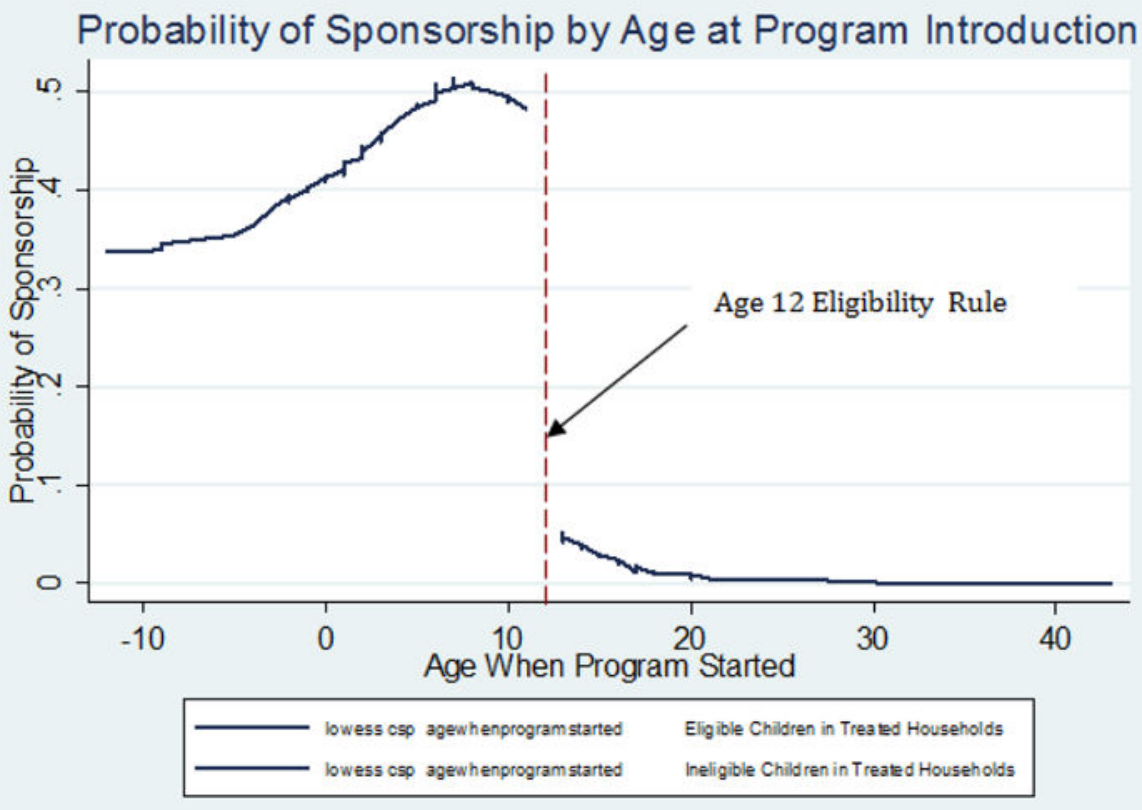

Figure 1.

Sponsorship as a Function of Age When Program Started 


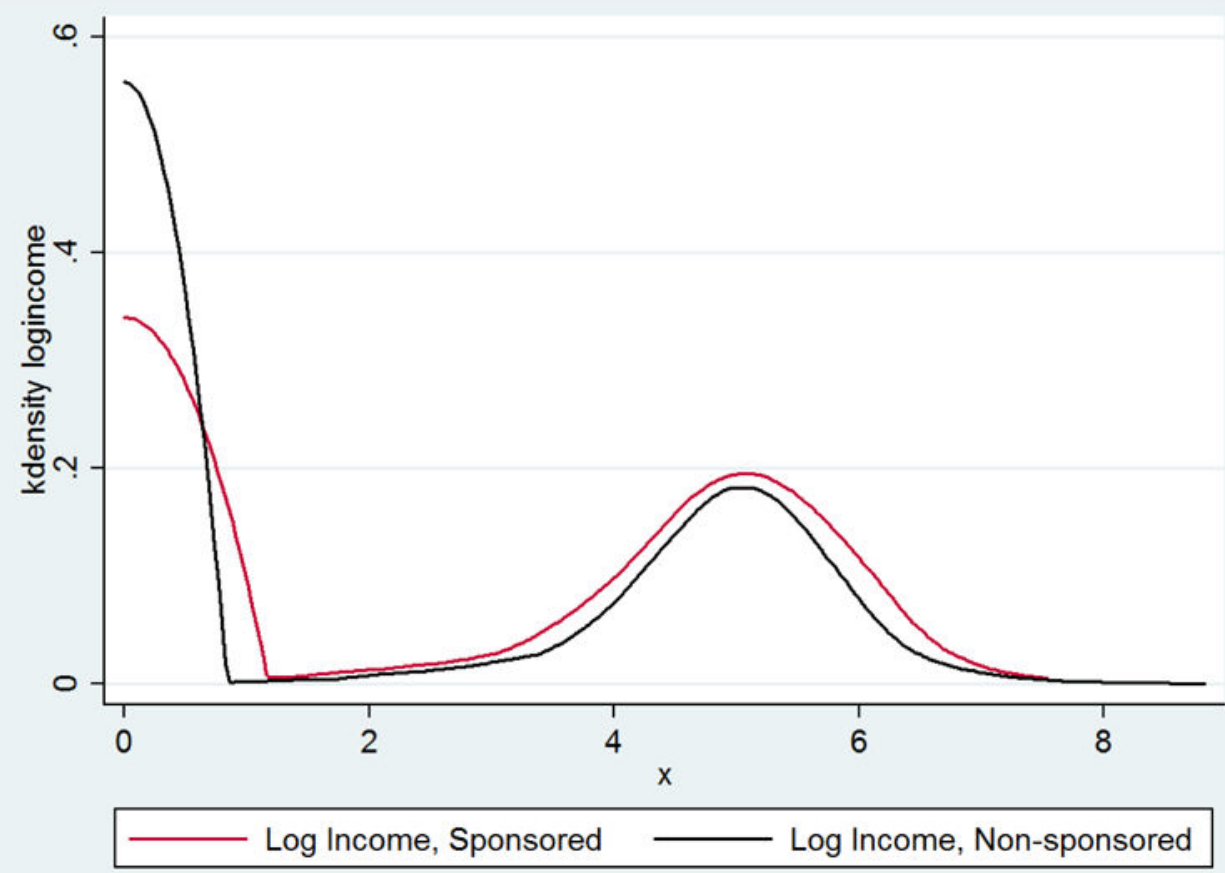

Figure 2.

Differences in Log Income, Sponsored vs. Unsponsored 


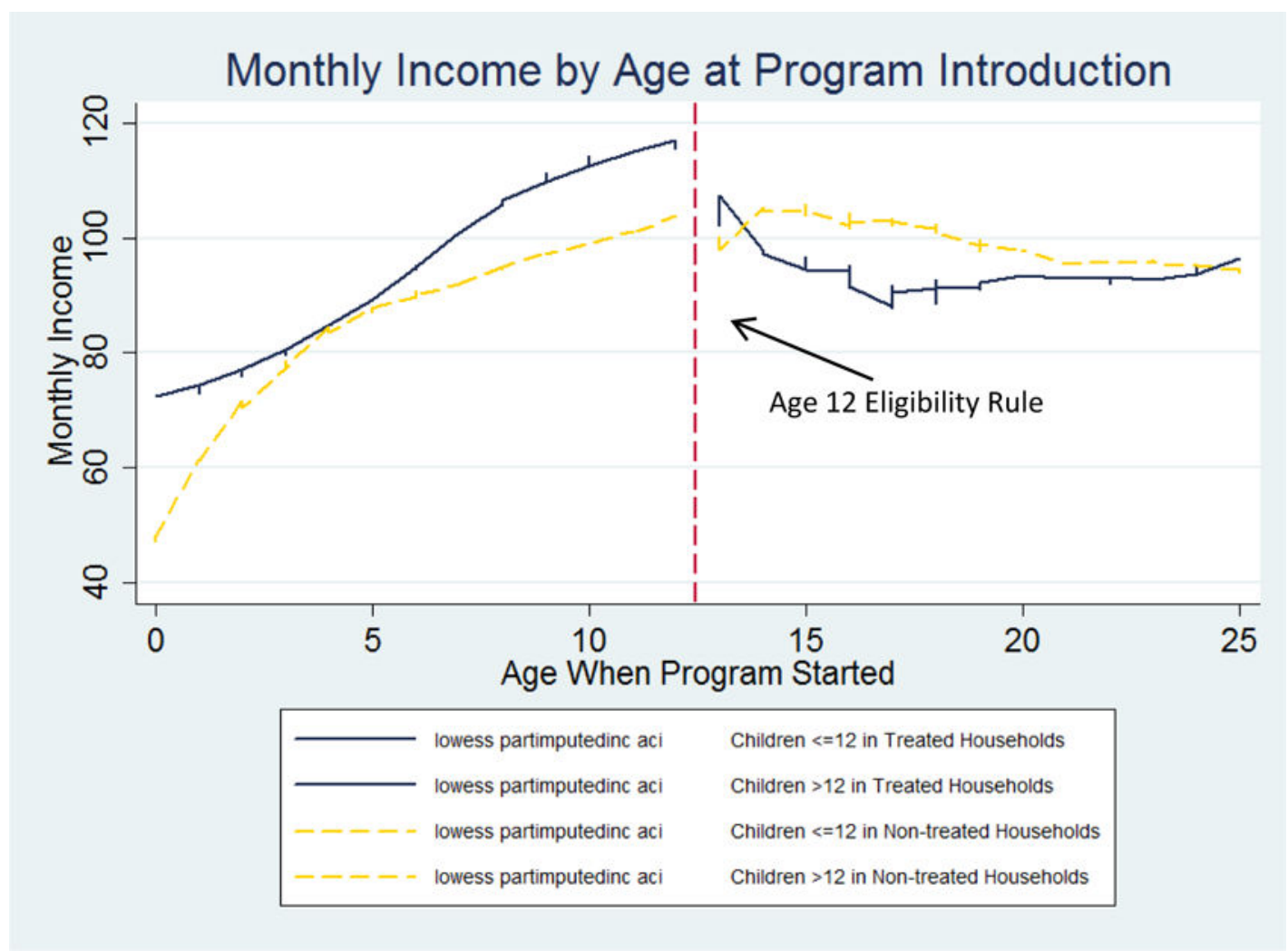

Figure 3.

Monthly Income as a Function of Eligibility 
Adult Monthly Income Sponsored vs. Non-Sponsored as Child

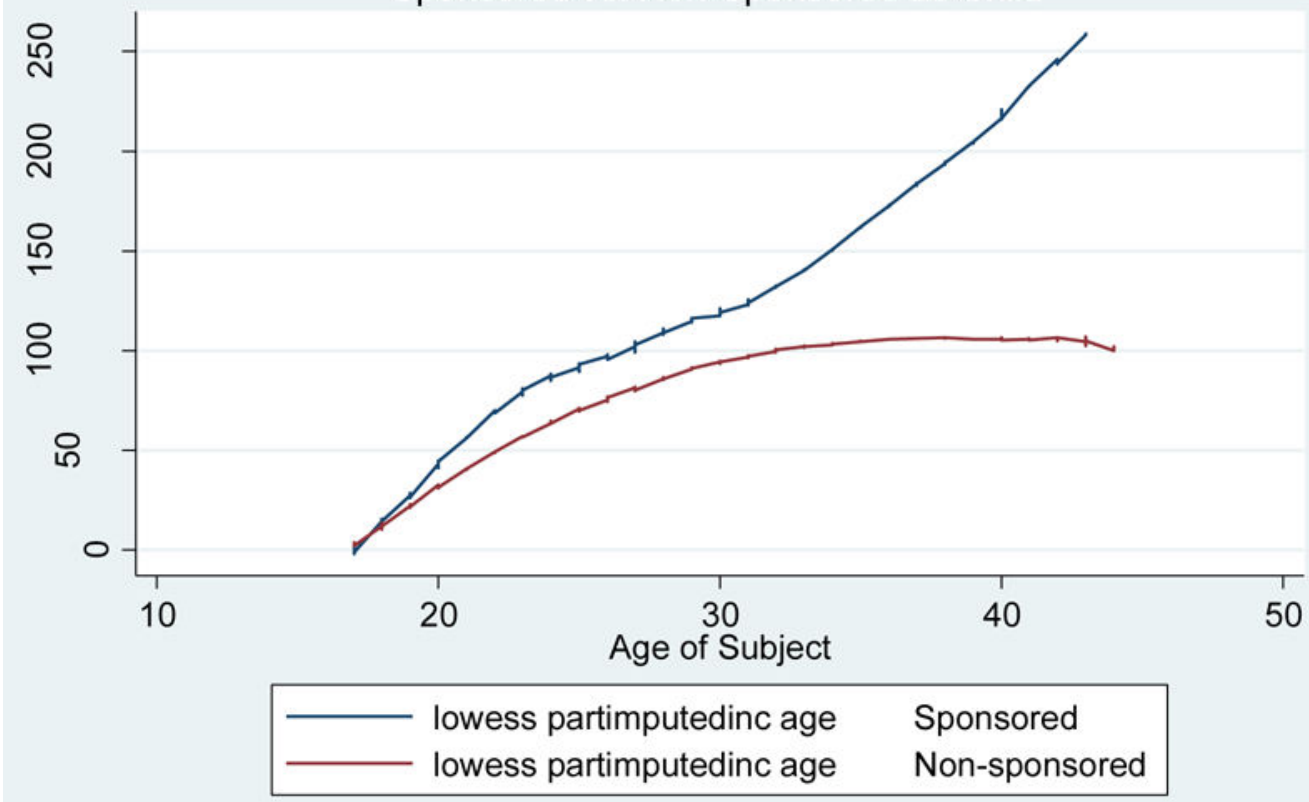

Figure 4.

Growth in Labor Income Gap Over Time, Sponsored vs. Non-Sponsored 


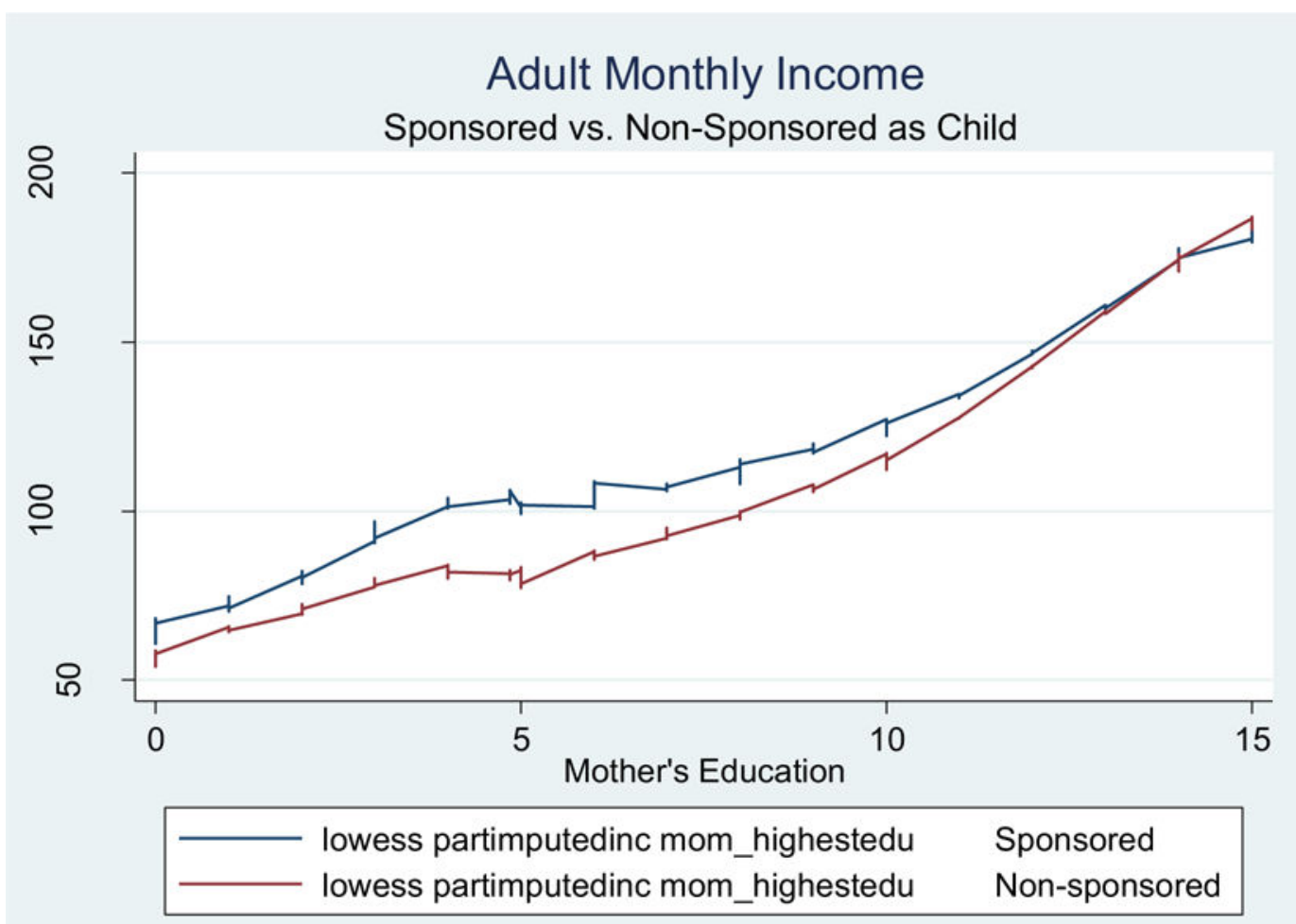

Figure 5.

Impact on Labor Income between Sponsored and Non-Sponsored by Mother's Education $($ Bandwidth $=0.5)$ 


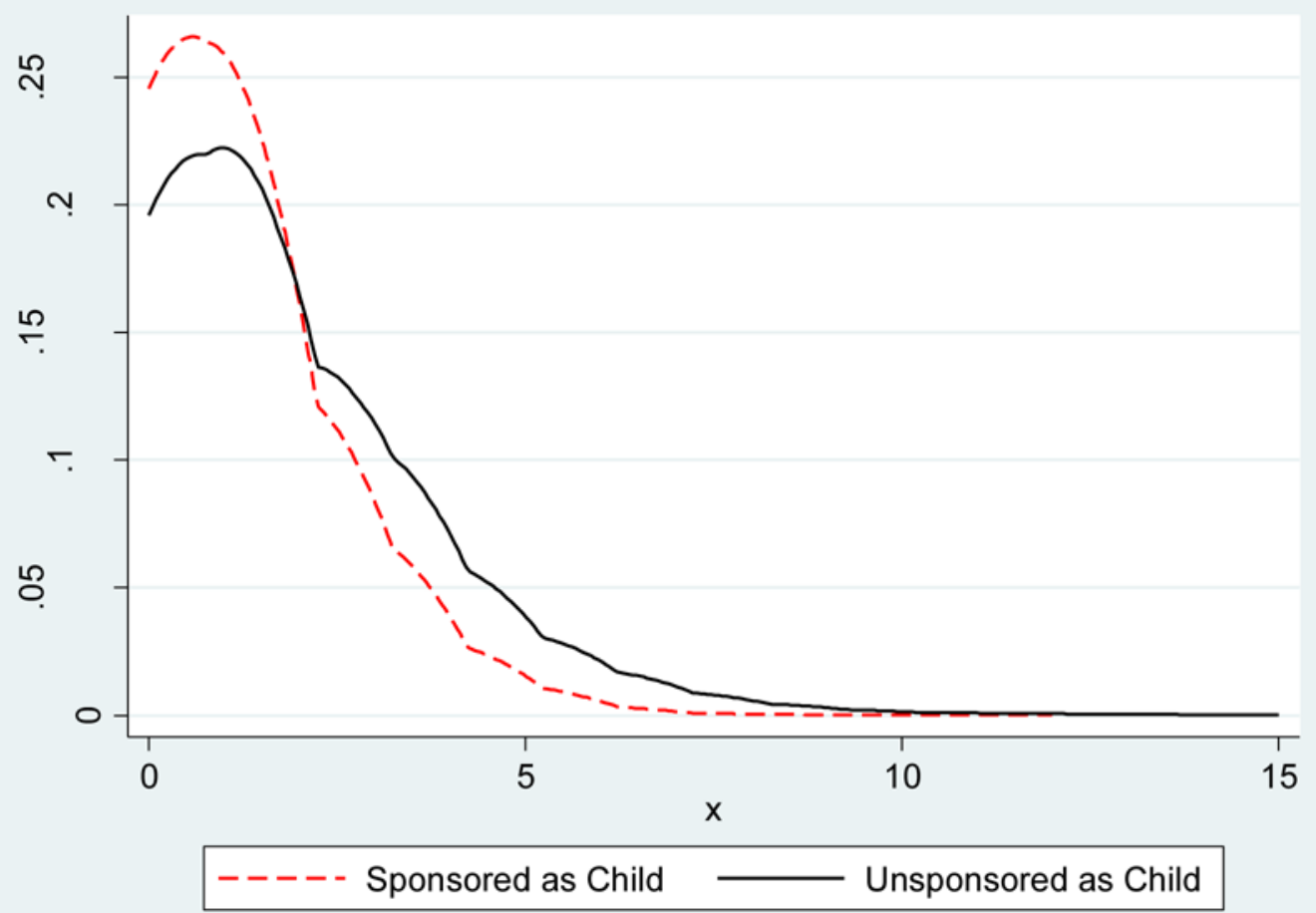

Figure 6.

Kernel Density of Number of Children by Sponsorship Status

World Bank Econ Rev. Author manuscript; available in PMC 2018 June 20. 


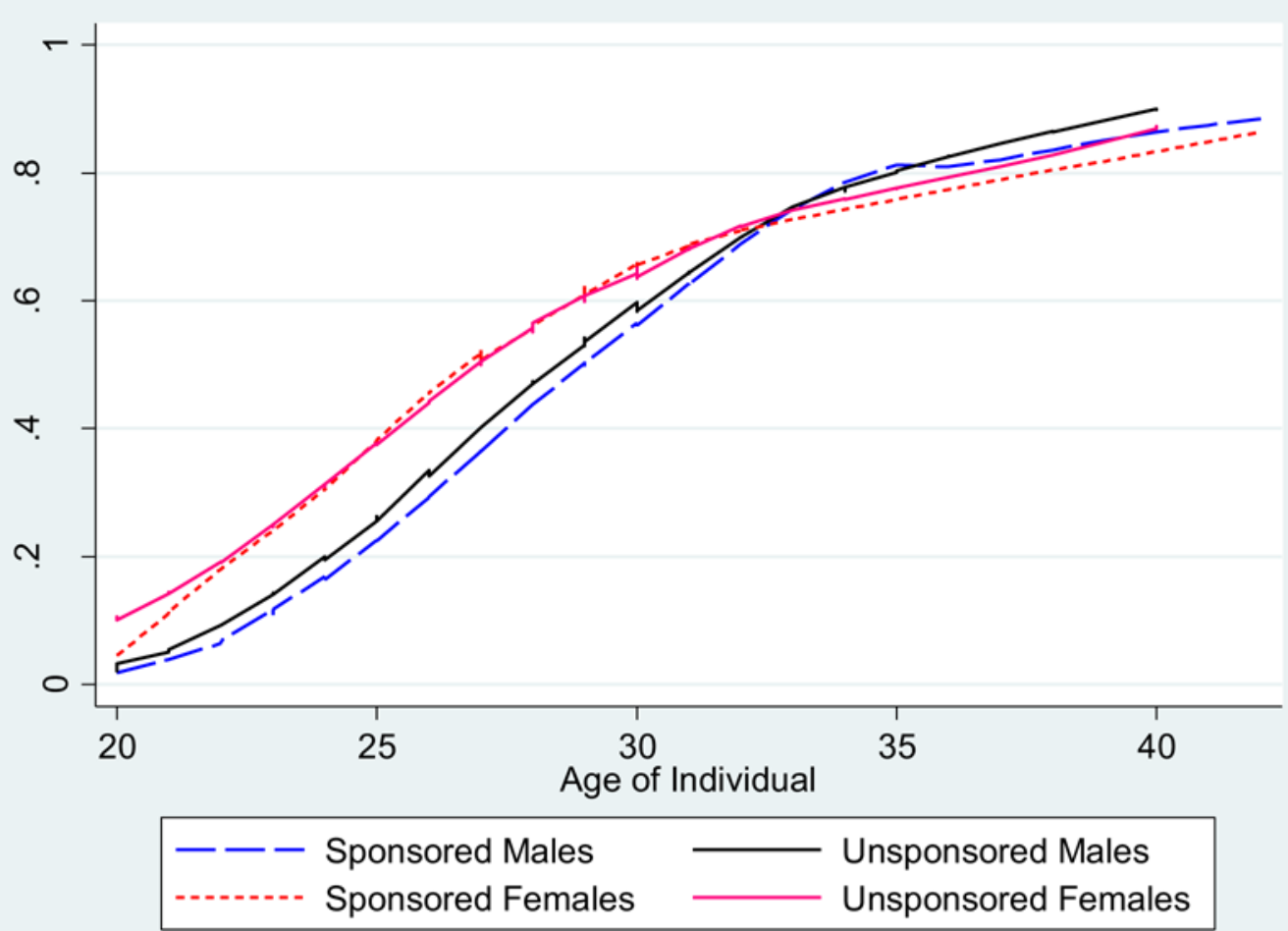

Figure 7.

Probability of Marriage by Sponsorship, Sex, and Age 


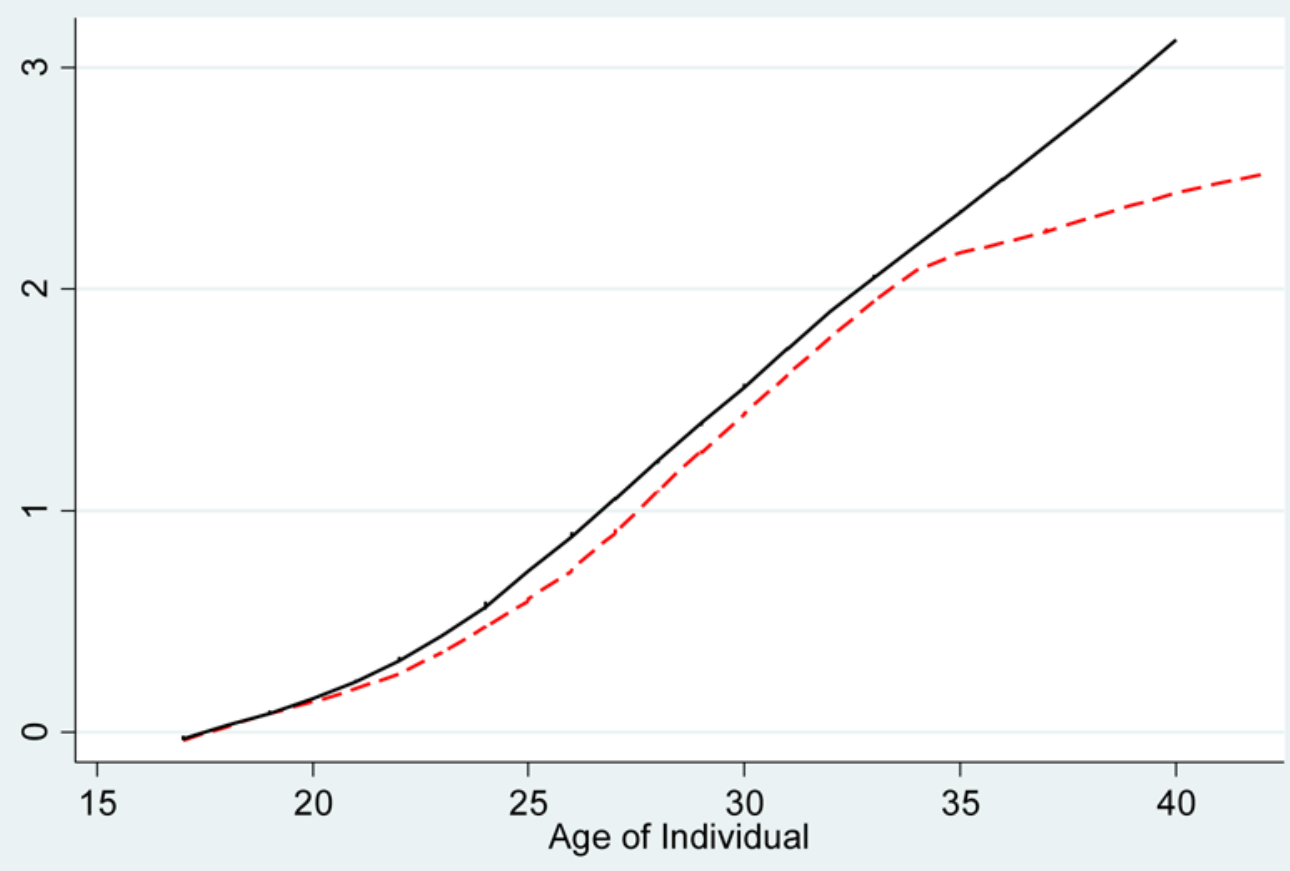

----- Sponsored as Child — Unsponsored as Child

Figure 8.

Number of Children in Adulthood by Age 


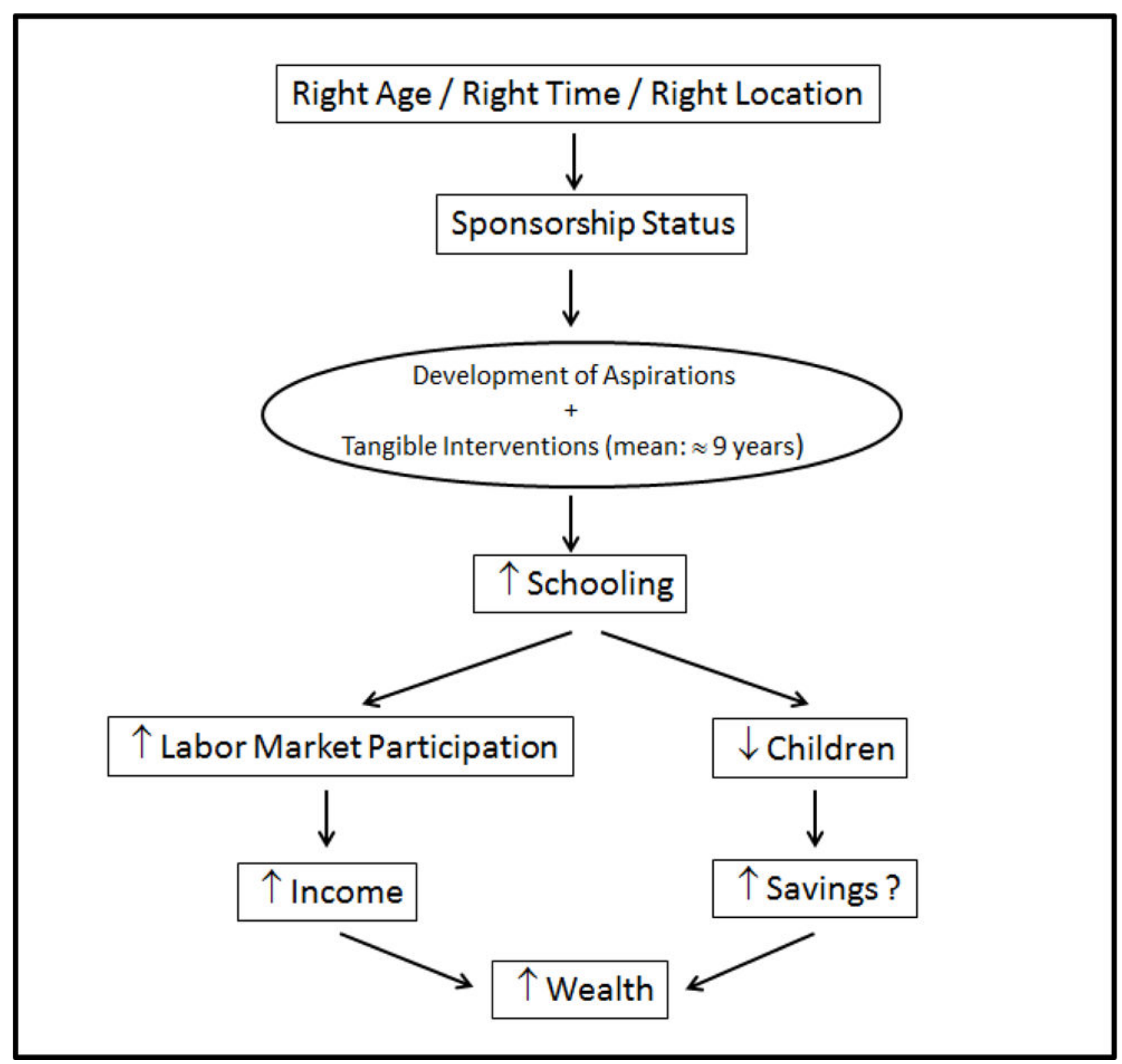

Figure 9.

Plausible Chain of Causal Effects from Sponsorship 


\section{Table 1}

\begin{tabular}{|c|c|c|c|}
\hline & Mean & Std. Dev. & Frequency \\
\hline Uganda & 11.02 & 3.53 & 188 \\
\hline Guatemala & 6.64 & 2.55 & 357 \\
\hline Philippines & 7.12 & 4.79 & 237 \\
\hline India & 10.86 & 3.53 & 221 \\
\hline Kenya & 10.13 & 3.43 & 543 \\
\hline Bolivia & 9.48 & 3.78 & 288 \\
\hline Total & 9.30 & 3.93 & 1,834 \\
\hline
\end{tabular}

Note: weighted mean is presented 


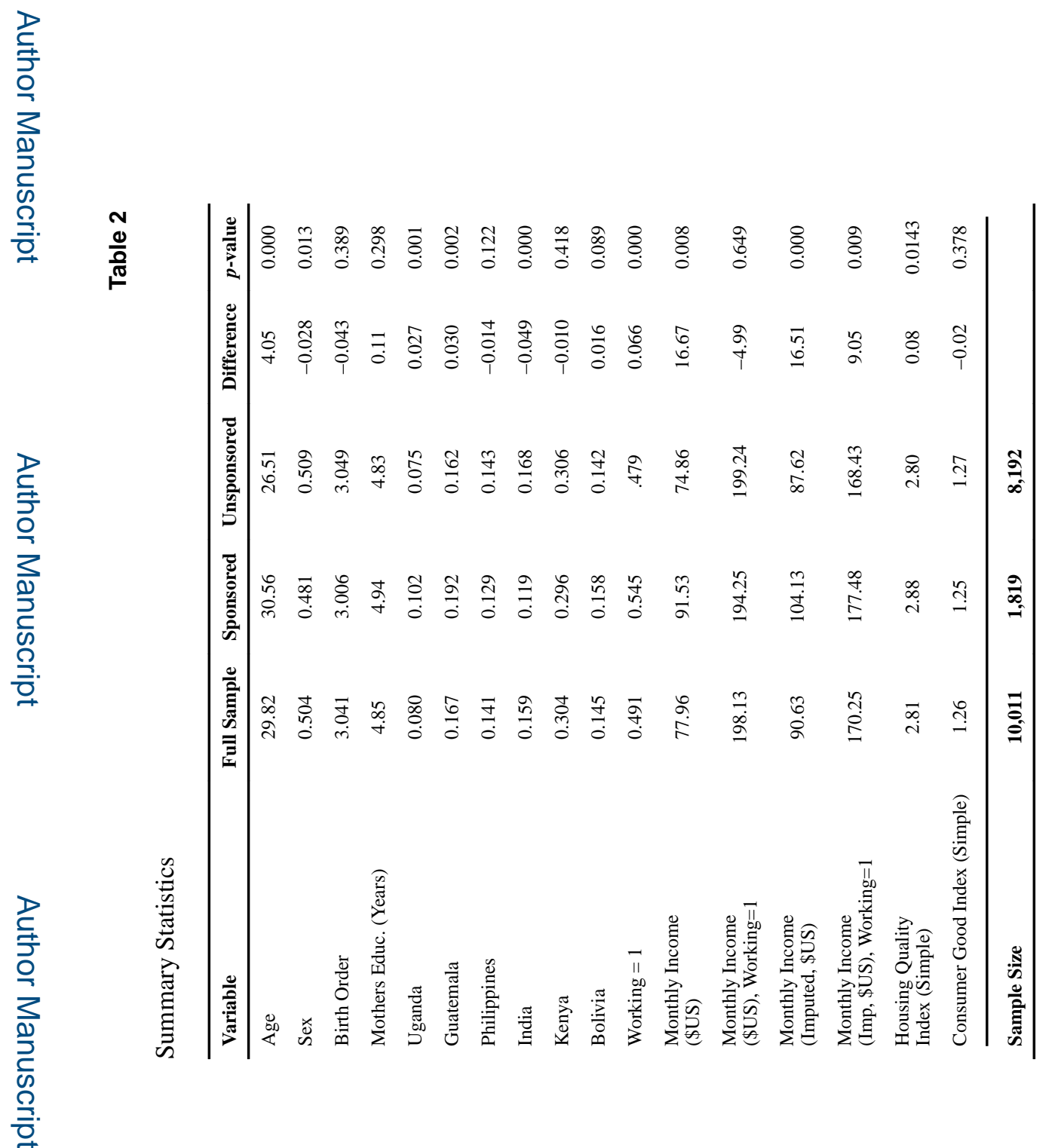

World Bank Econ Rev. Author manuscript; available in PMC 2018 June 20. 


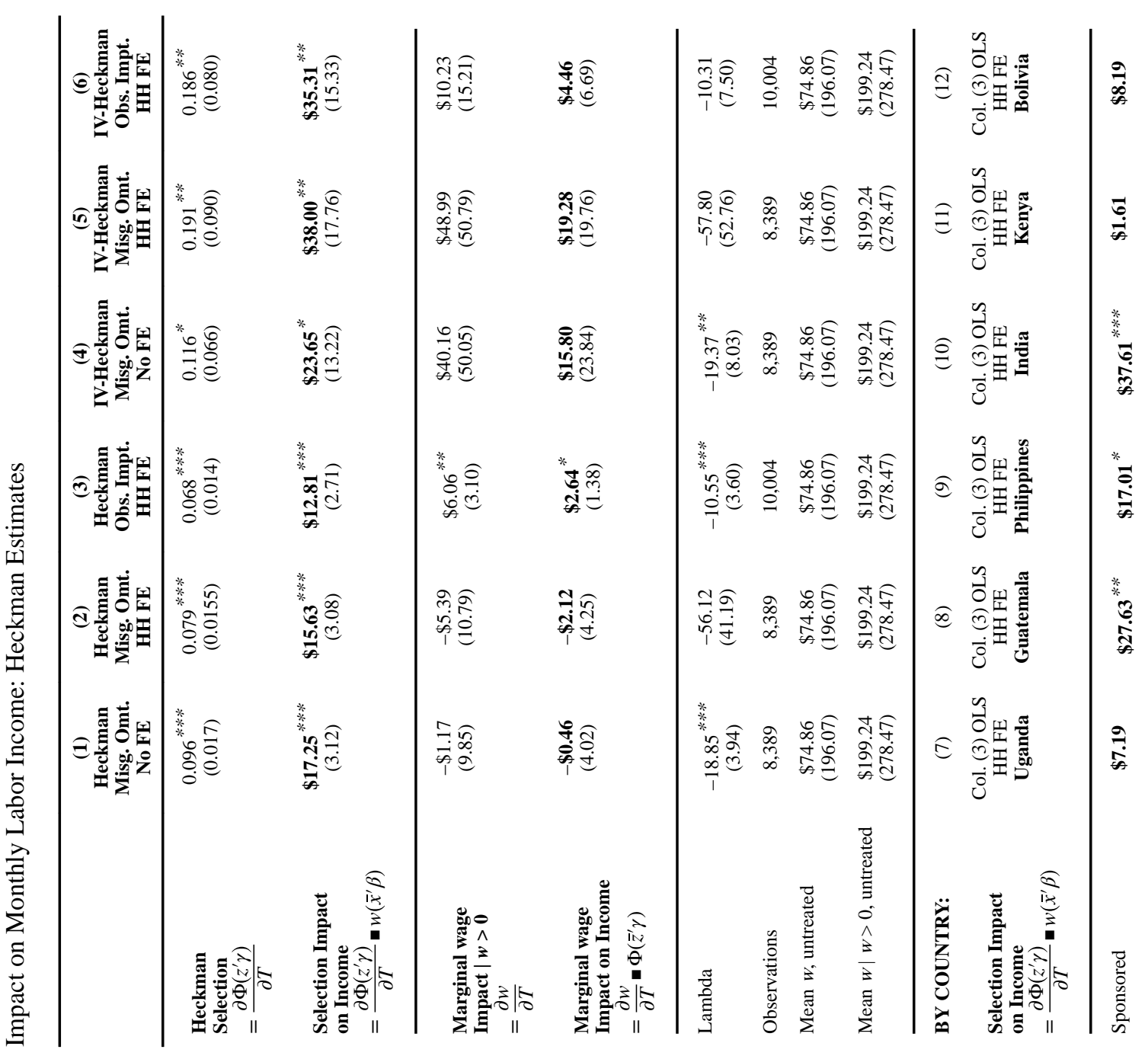

World Bank Econ Rev. Author manuscript; available in PMC 2018 June 20. 


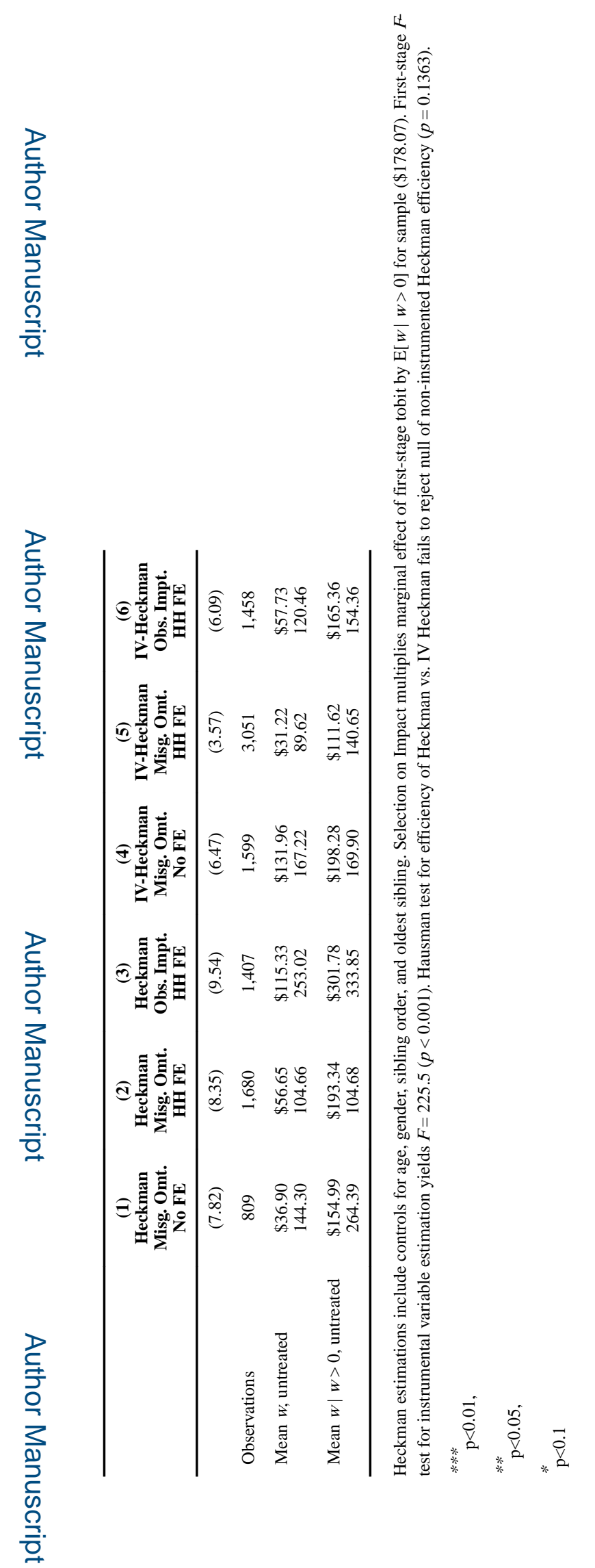

World Bank Econ Rev. Author manuscript; available in PMC 2018 June 20. 
I

焉

를

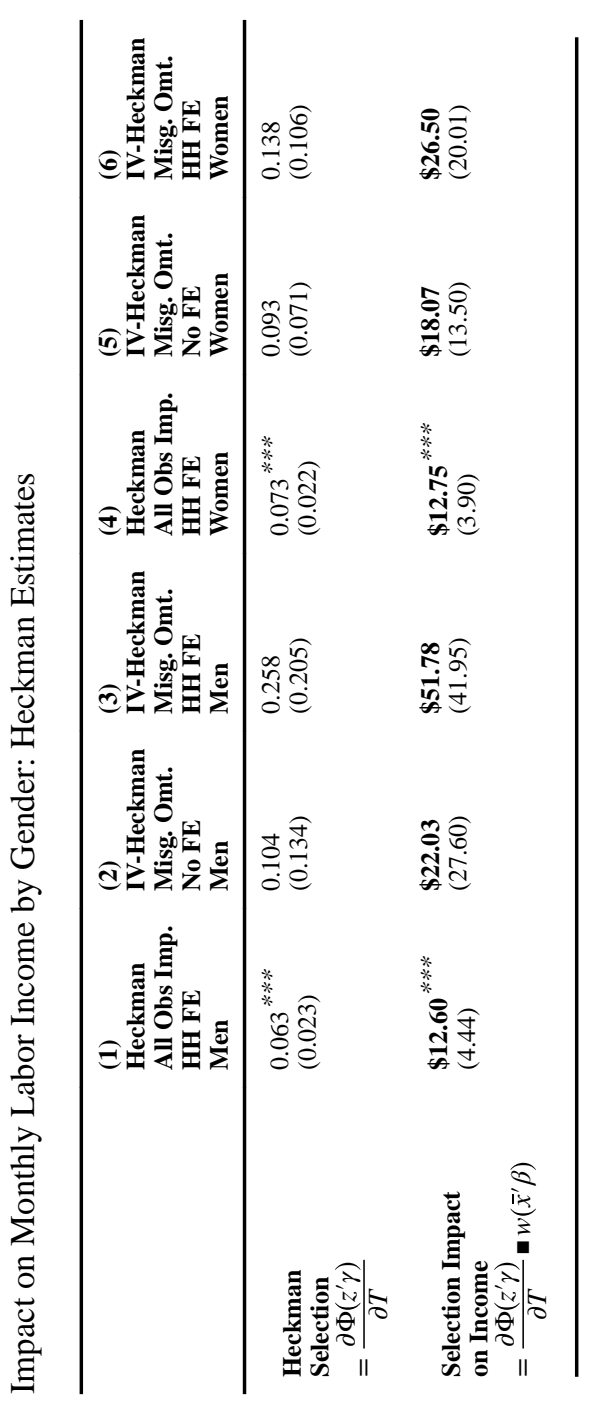

\begin{tabular}{|c|c|c|c|c|}
\hline 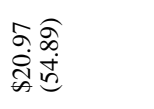 & 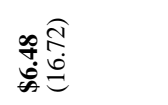 & 宅 & 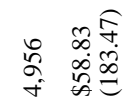 & 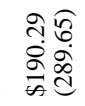 \\
\hline 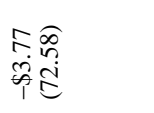 & 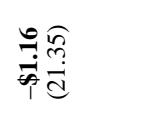 & 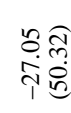 & 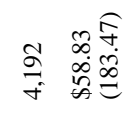 & 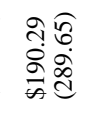 \\
\hline 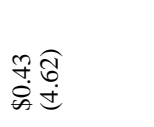 & 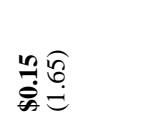 & 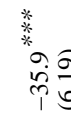 & 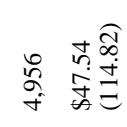 & 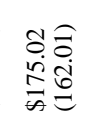 \\
\hline 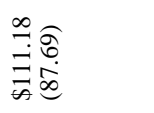 & 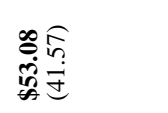 & 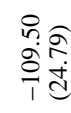 & 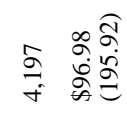 & 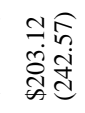 \\
\hline 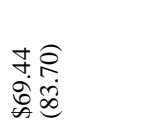 & 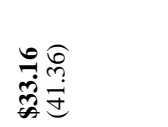 & 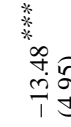 & 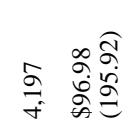 & 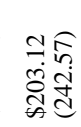 \\
\hline 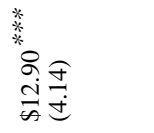 & 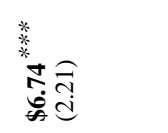 & 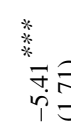 & 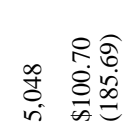 & 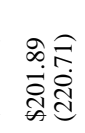 \\
\hline 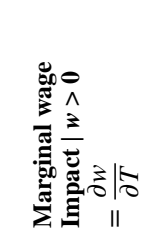 & 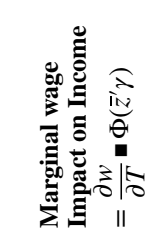 & 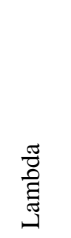 & 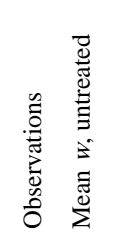 & 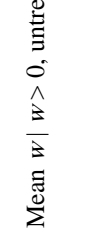 \\
\hline
\end{tabular}

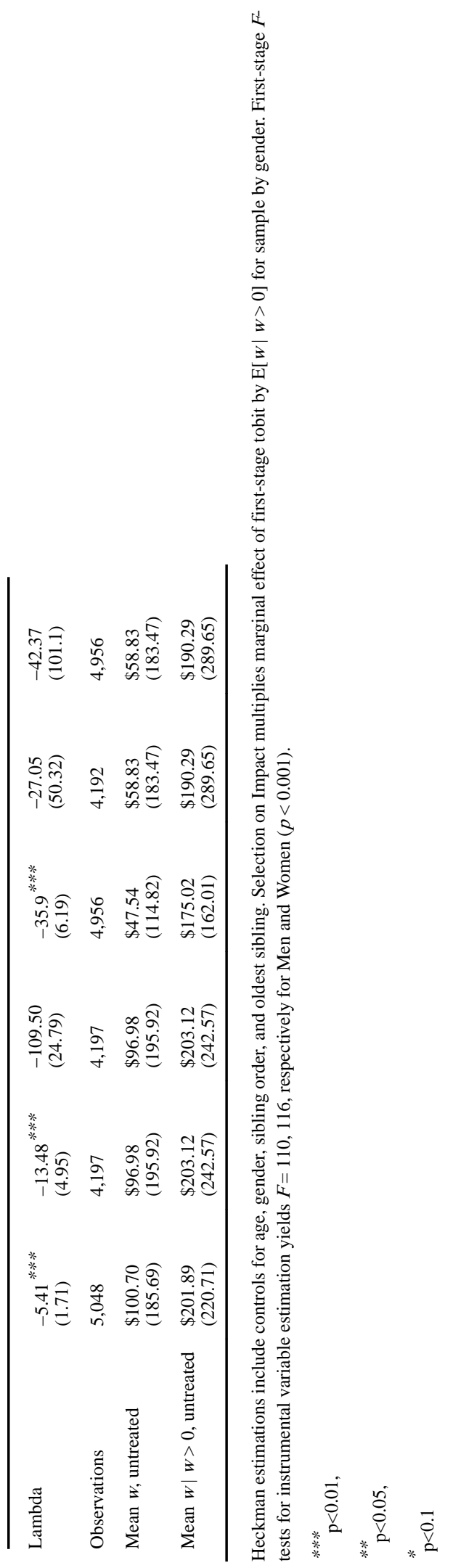

World Bank Econ Rev. Author manuscript; available in PMC 2018 June 20. 


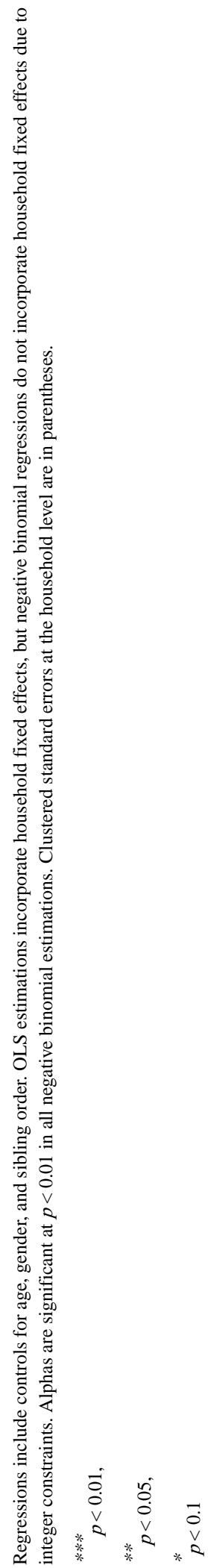

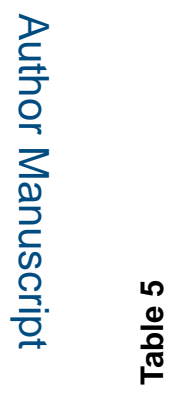

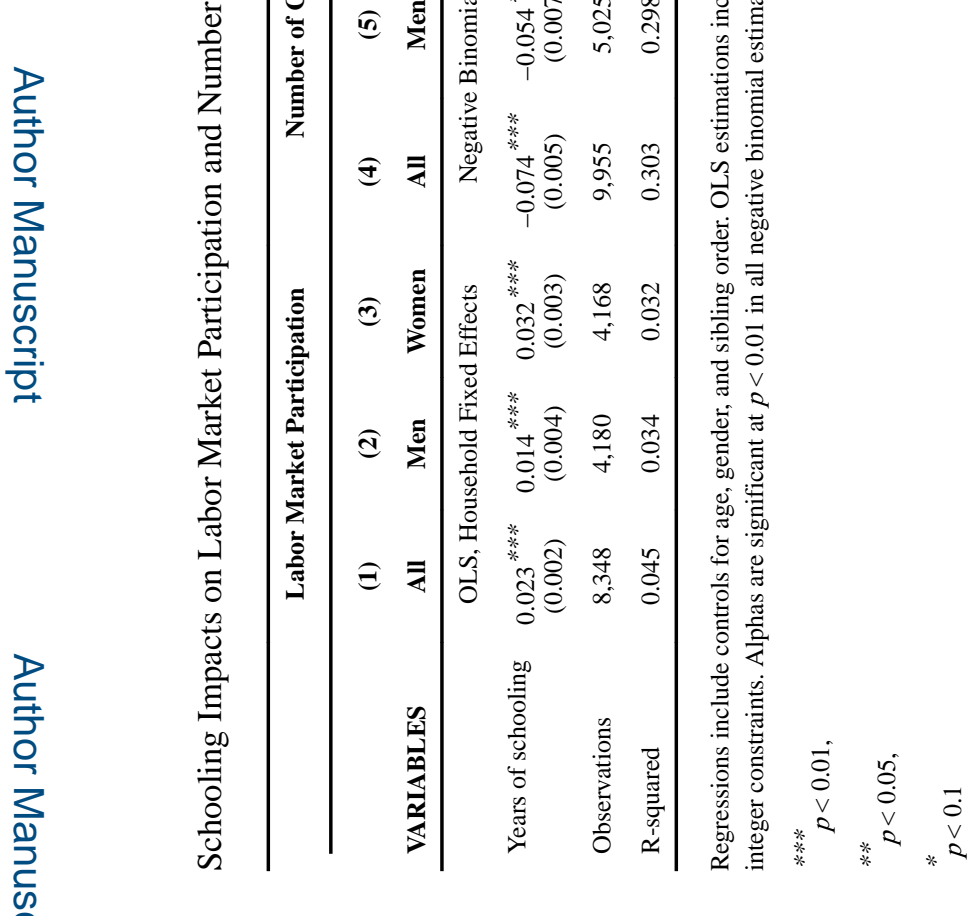

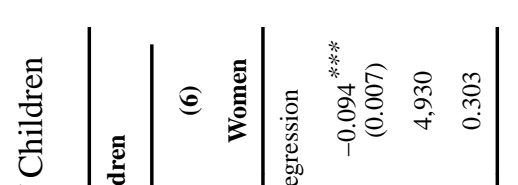
पू World Bank Econ Rev. Author manuscript; available in PMC 2018 June 20. 


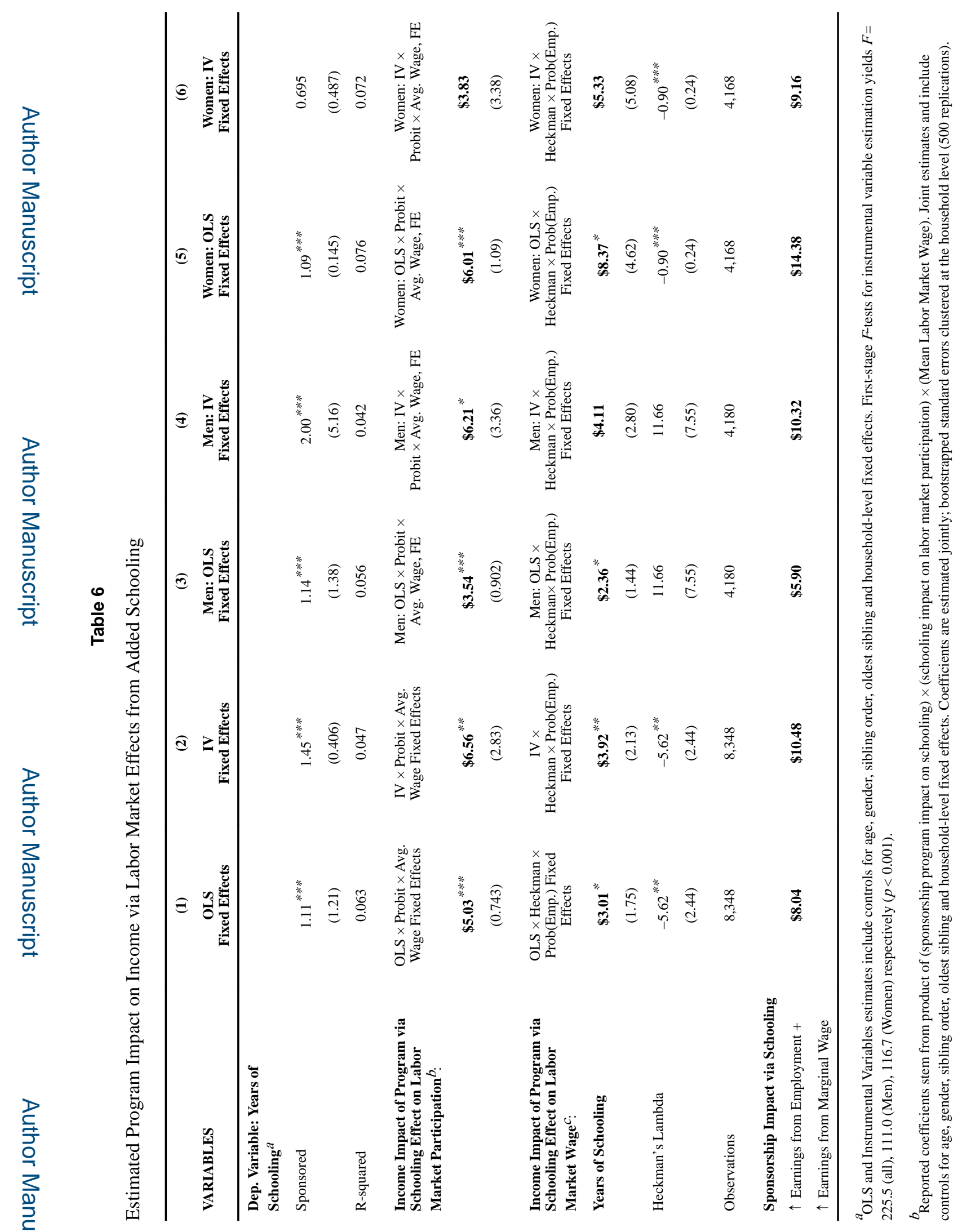

World Bank Econ Rev. Author manuscript; available in PMC 2018 June 20. 


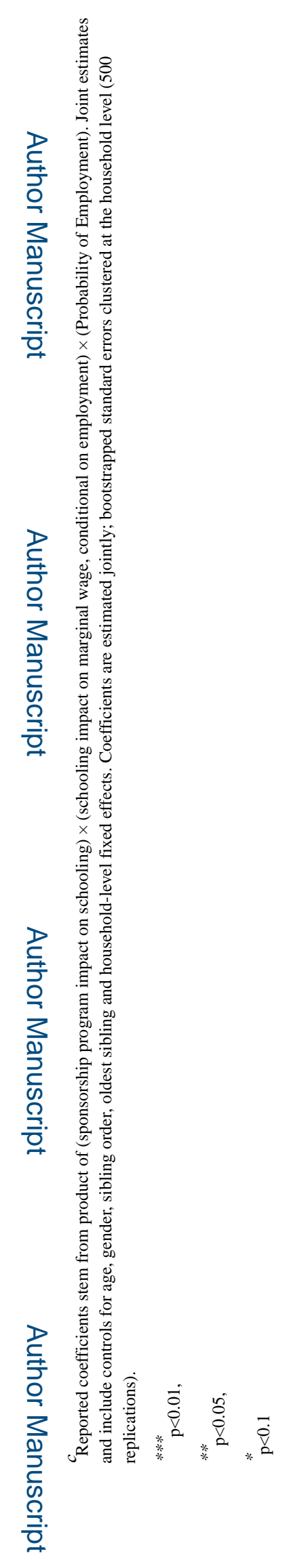

World Bank Econ Rev. Author manuscript; available in PMC 2018 June 20. 


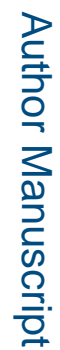

옹

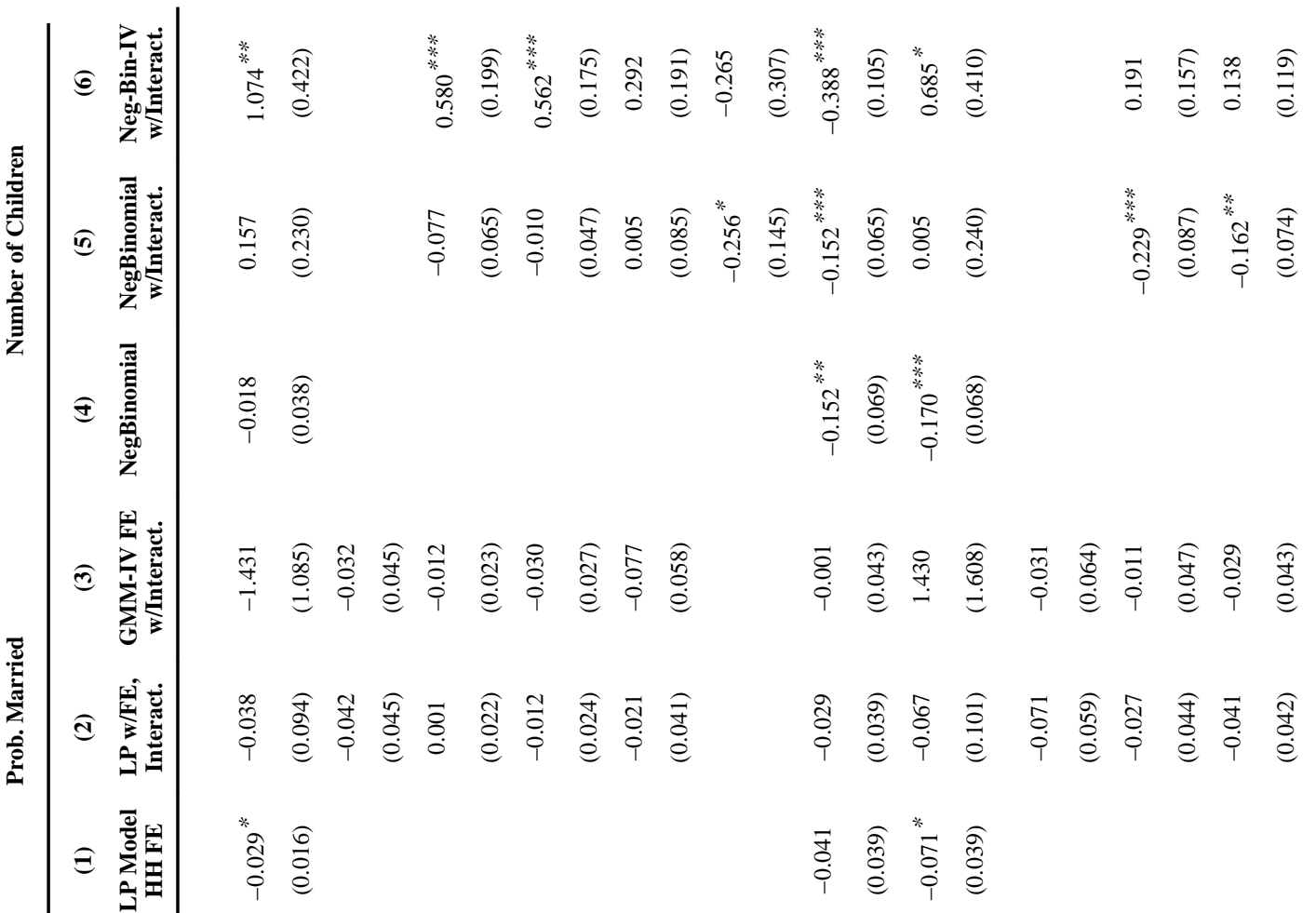

ᄅ

?

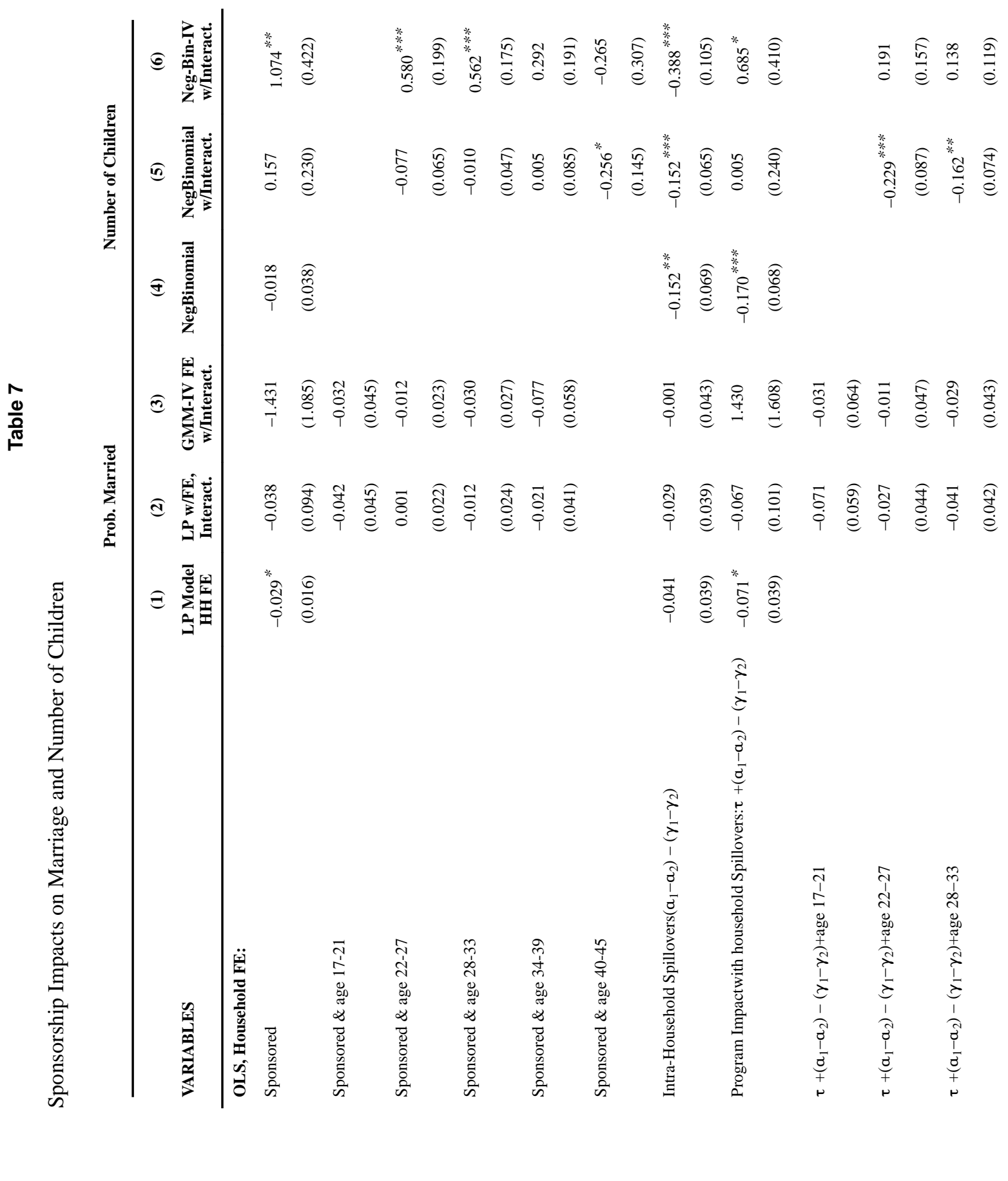

World Bank Econ Rev. Author manuscript; available in PMC 2018 June 20. 
Wydick et al.

Page 34

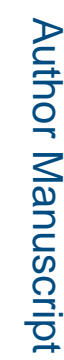

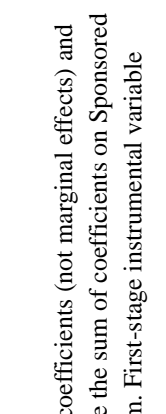

$$
\text { (0) }
$$

ᄅ্

ᄅ্য

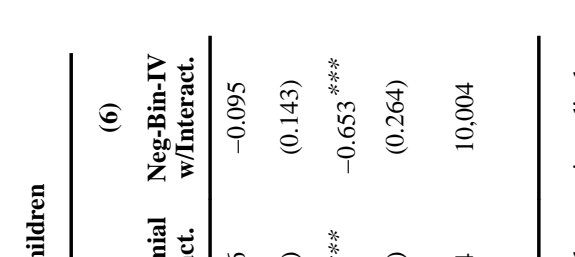

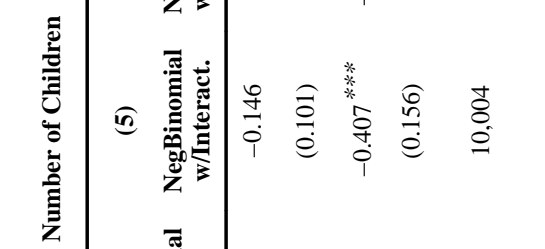

4

王

$\int$

a

离

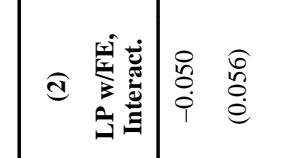

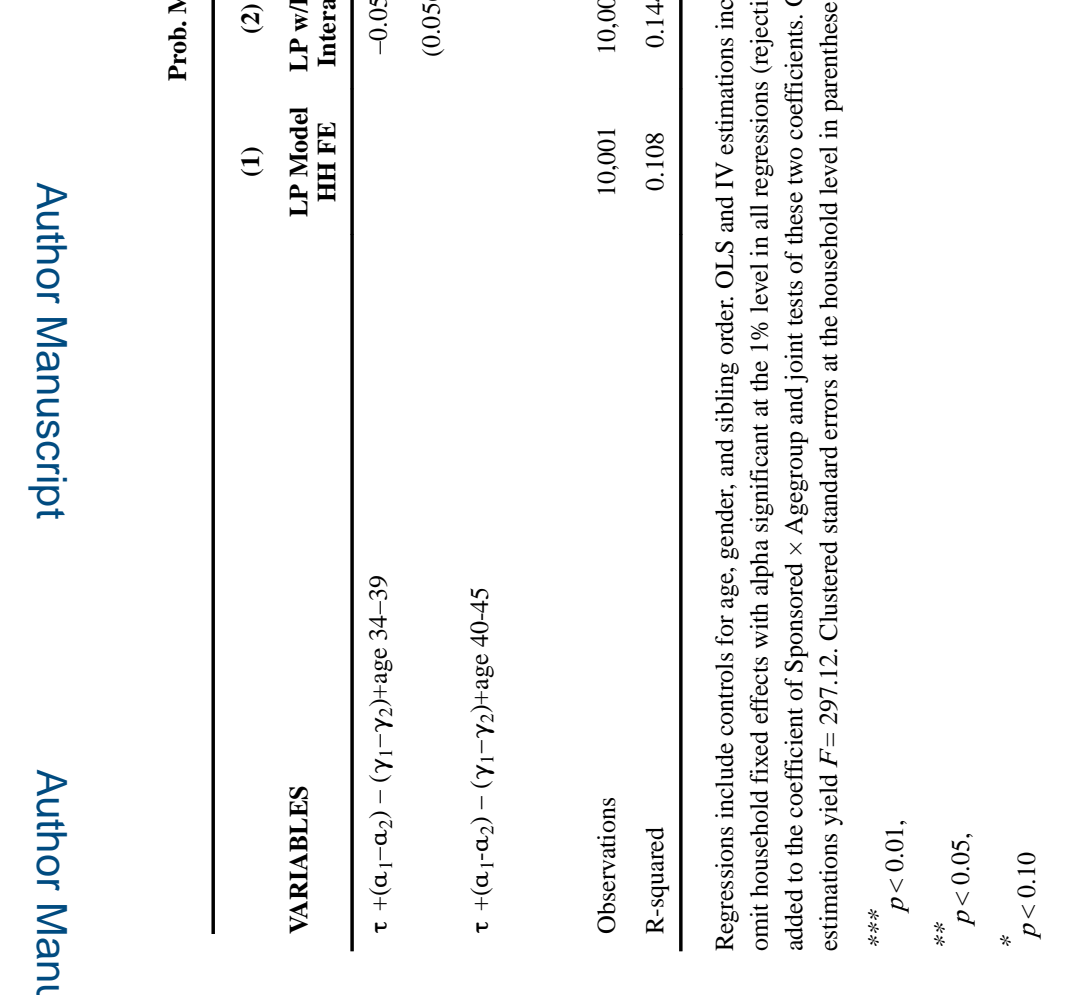

World Bank Econ Rev. Author manuscript; available in PMC 2018 June 20. 


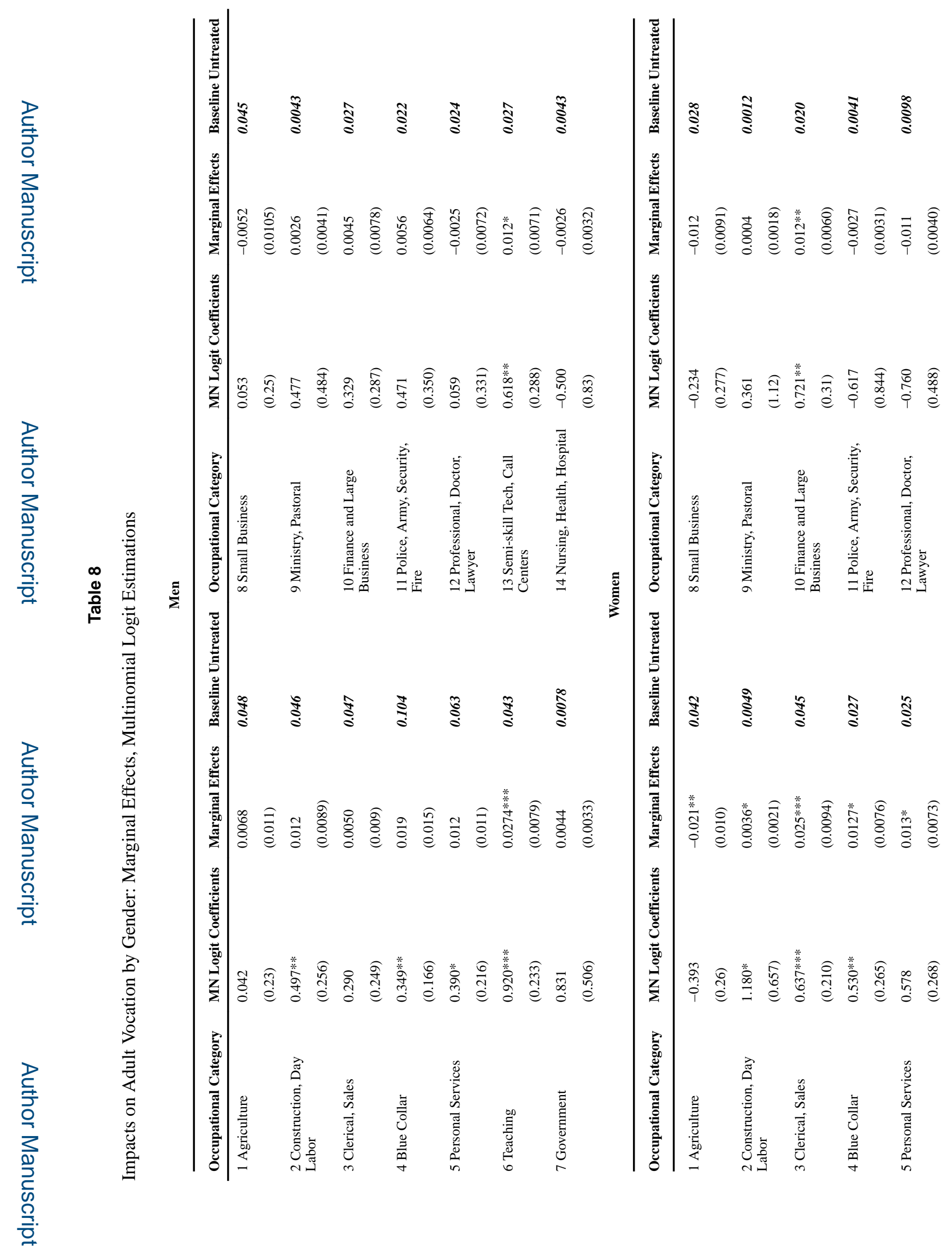

World Bank Econ Rev. Author manuscript; available in PMC 2018 June 20. 
Wydick et al.

Page 36

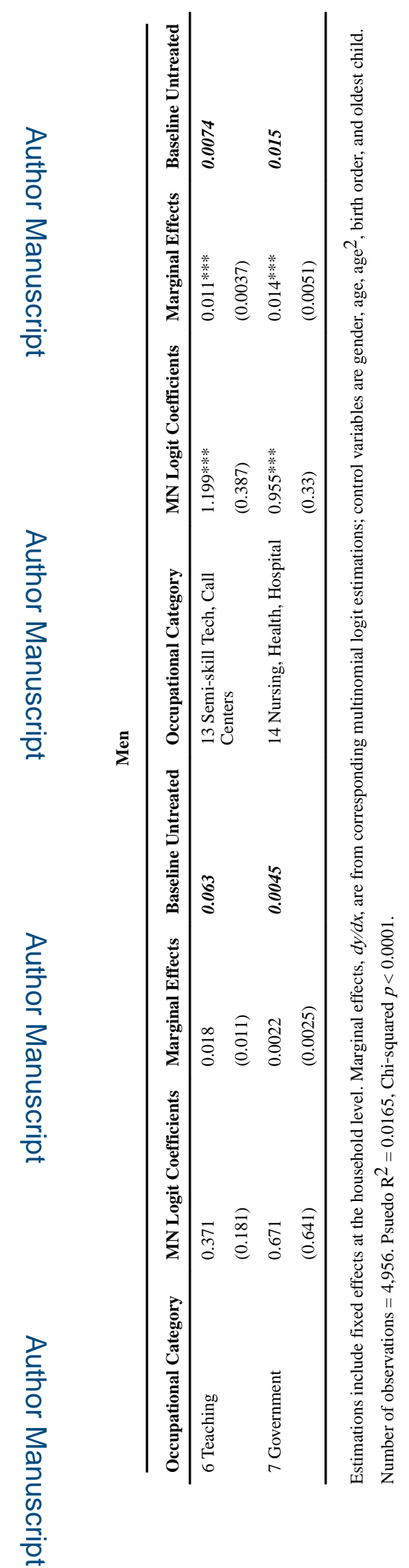

World Bank Econ Rev. Author manuscript; available in PMC 2018 June 20. 

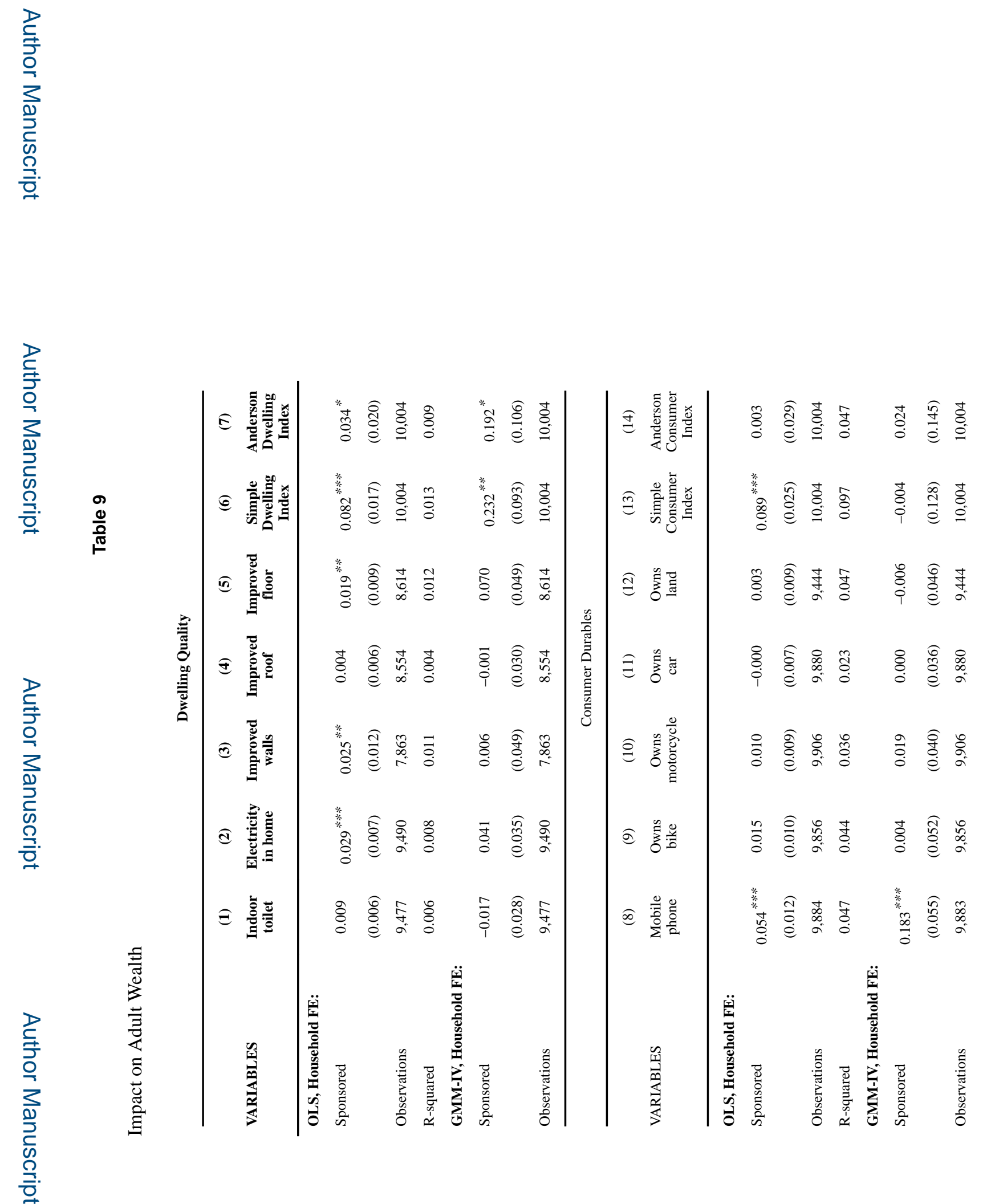

World Bank Econ Rev. Author manuscript; available in PMC 2018 June 20. 


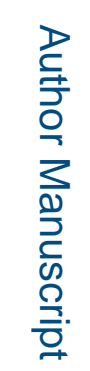

롱 


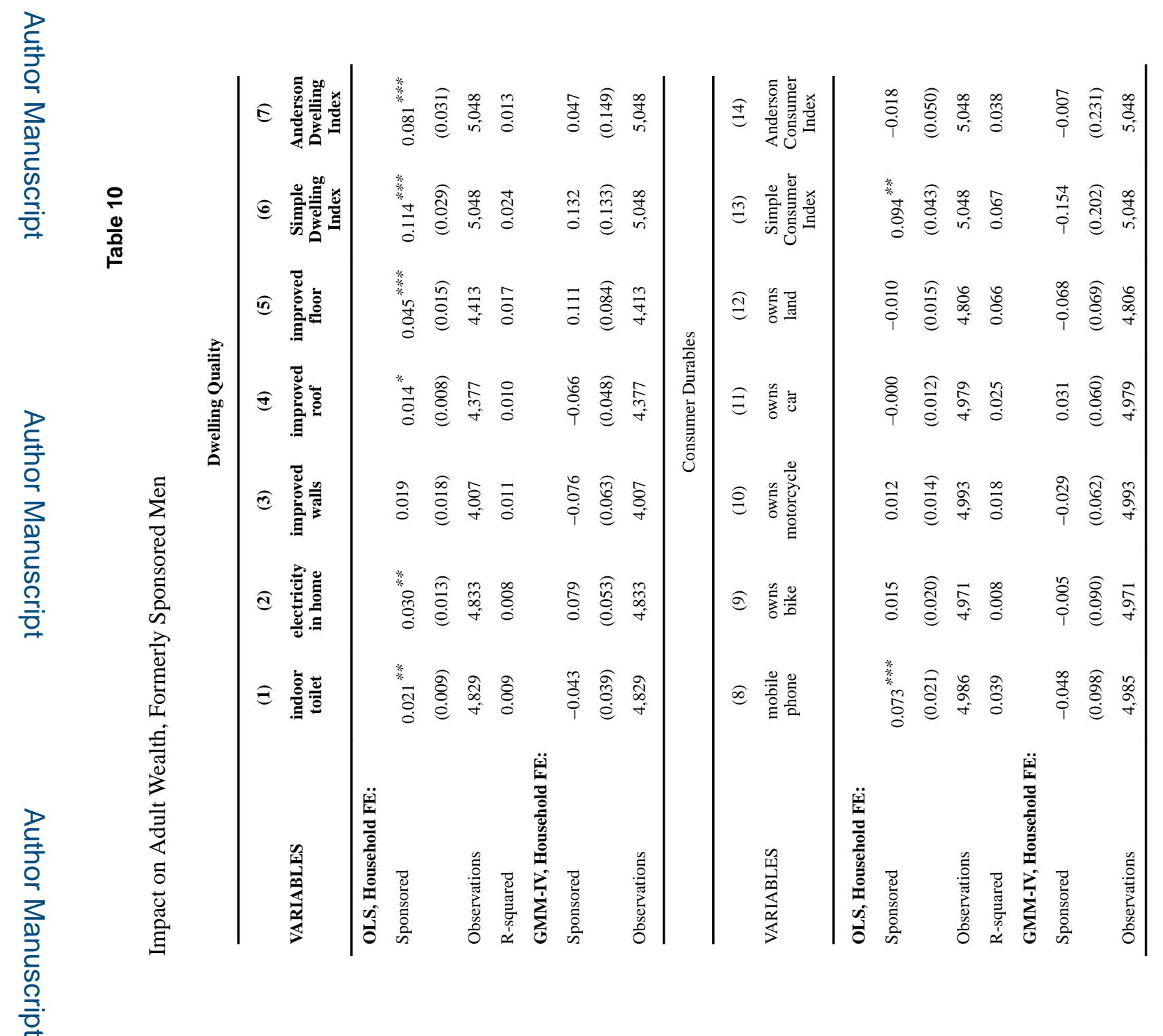

World Bank Econ Rev. Author manuscript; available in PMC 2018 June 20. 


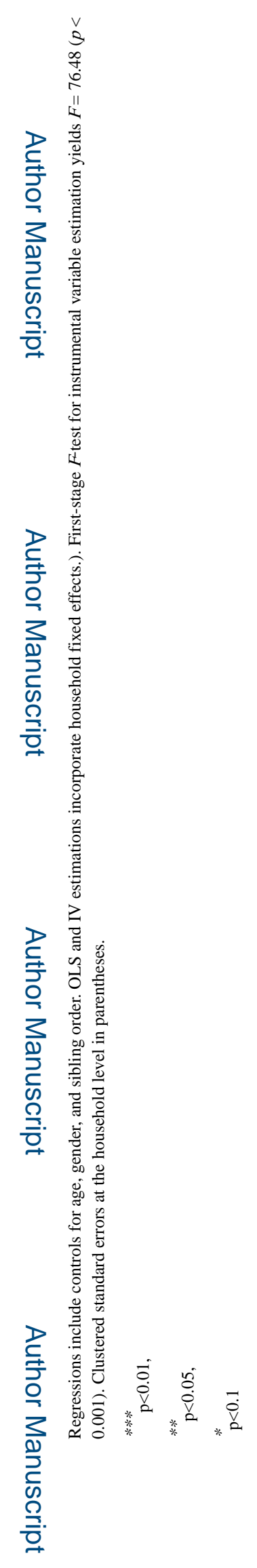

World Bank Econ Rev. Author manuscript; available in PMC 2018 June 20. 


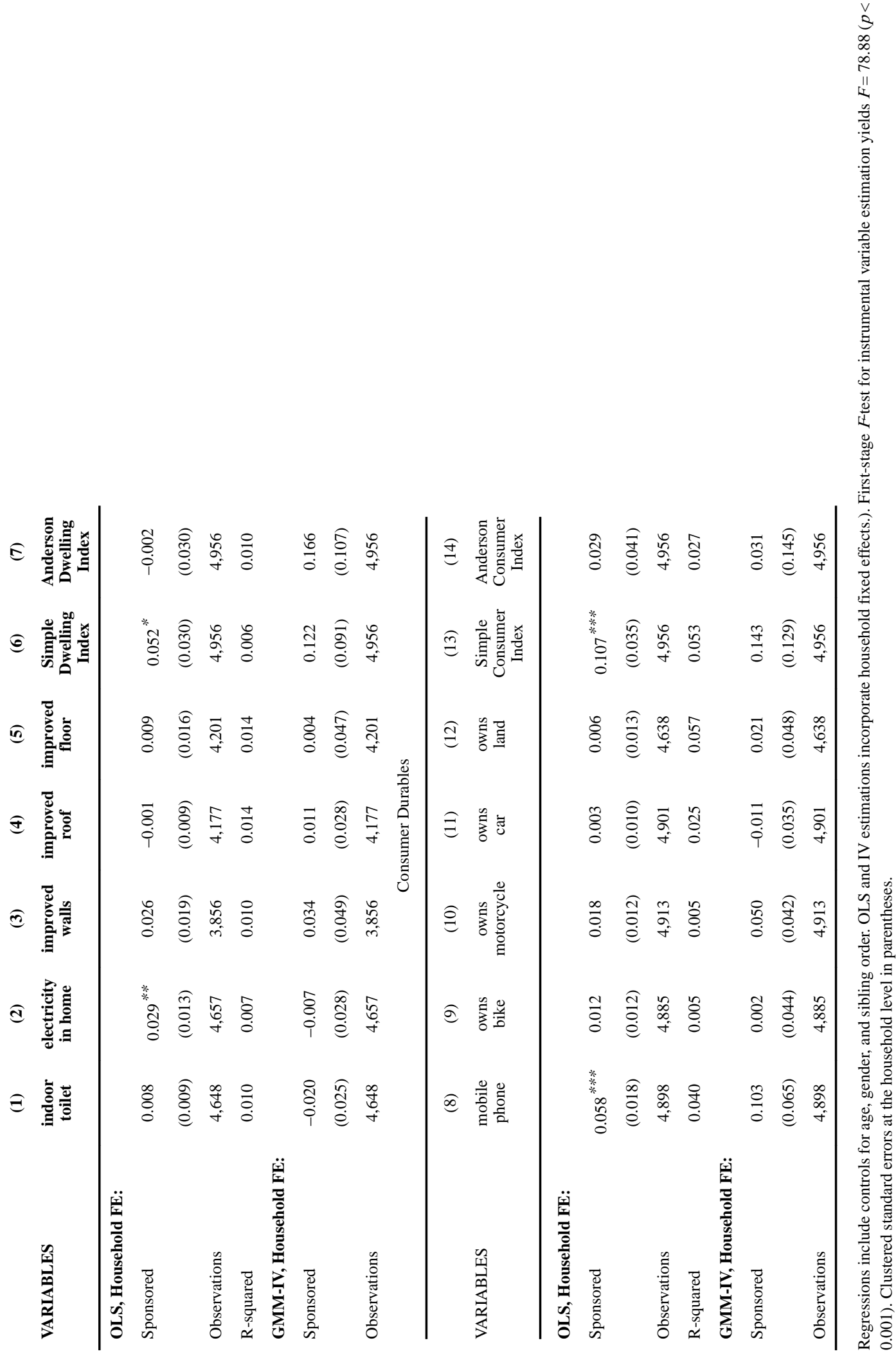

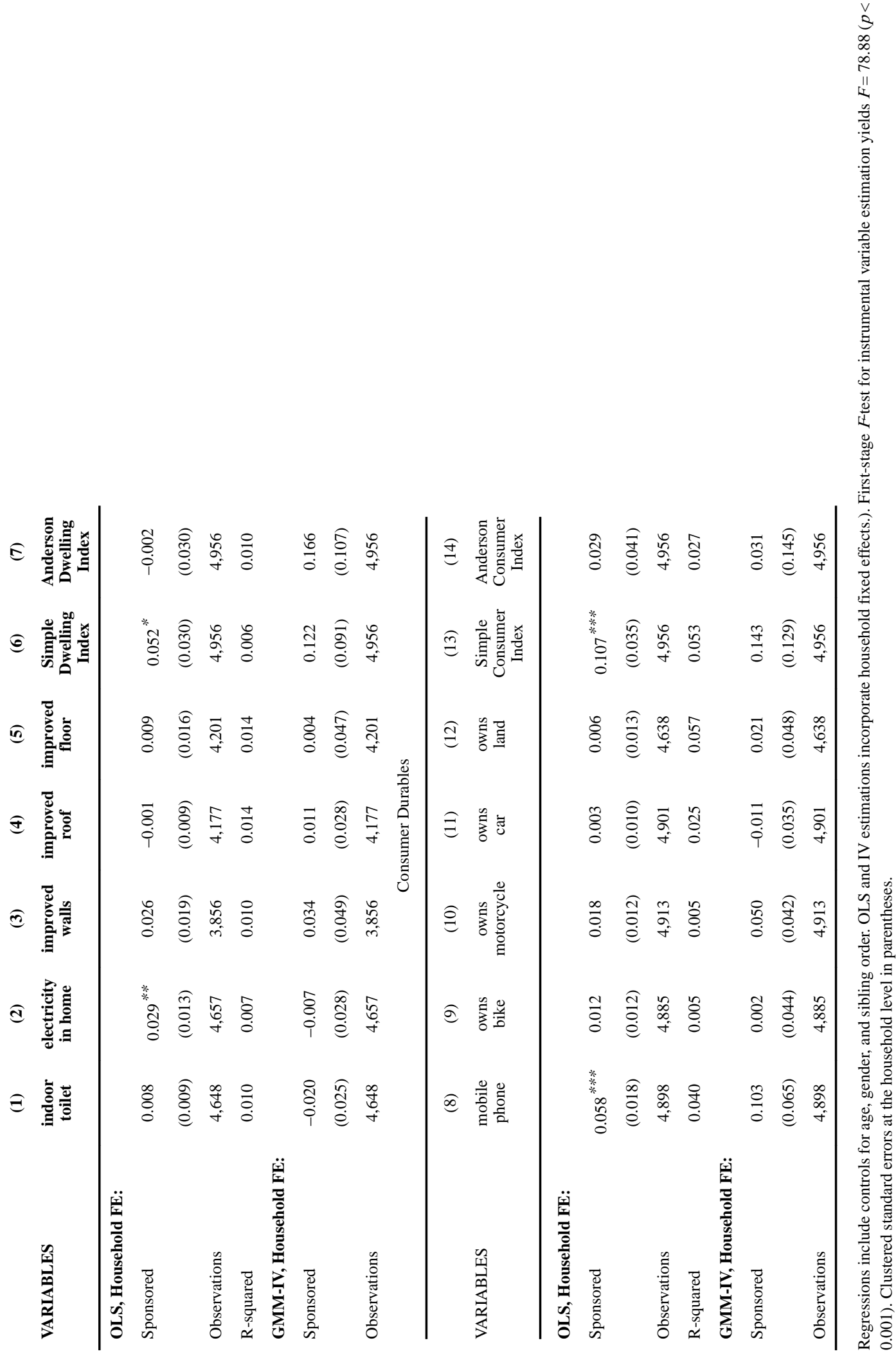

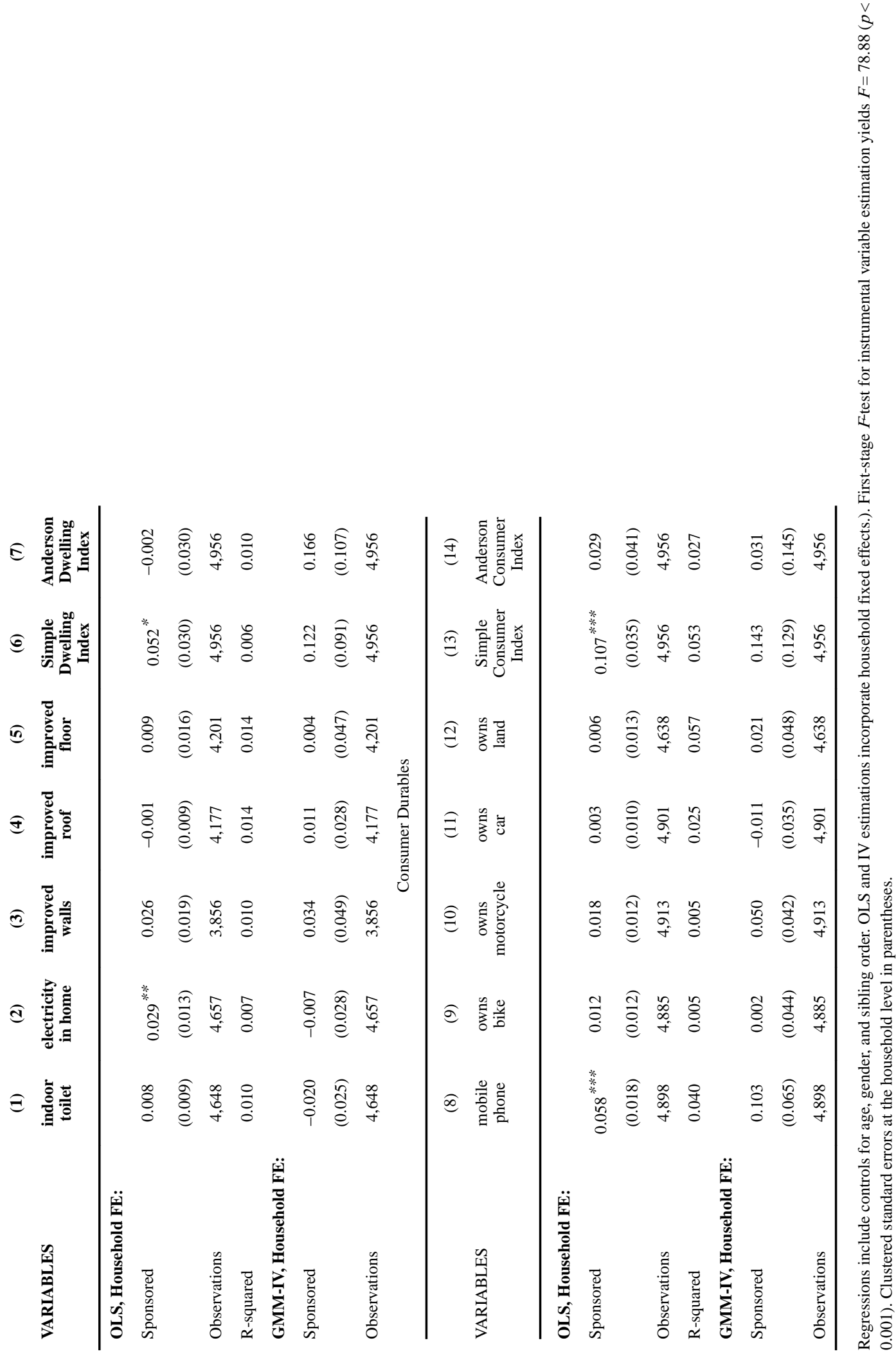

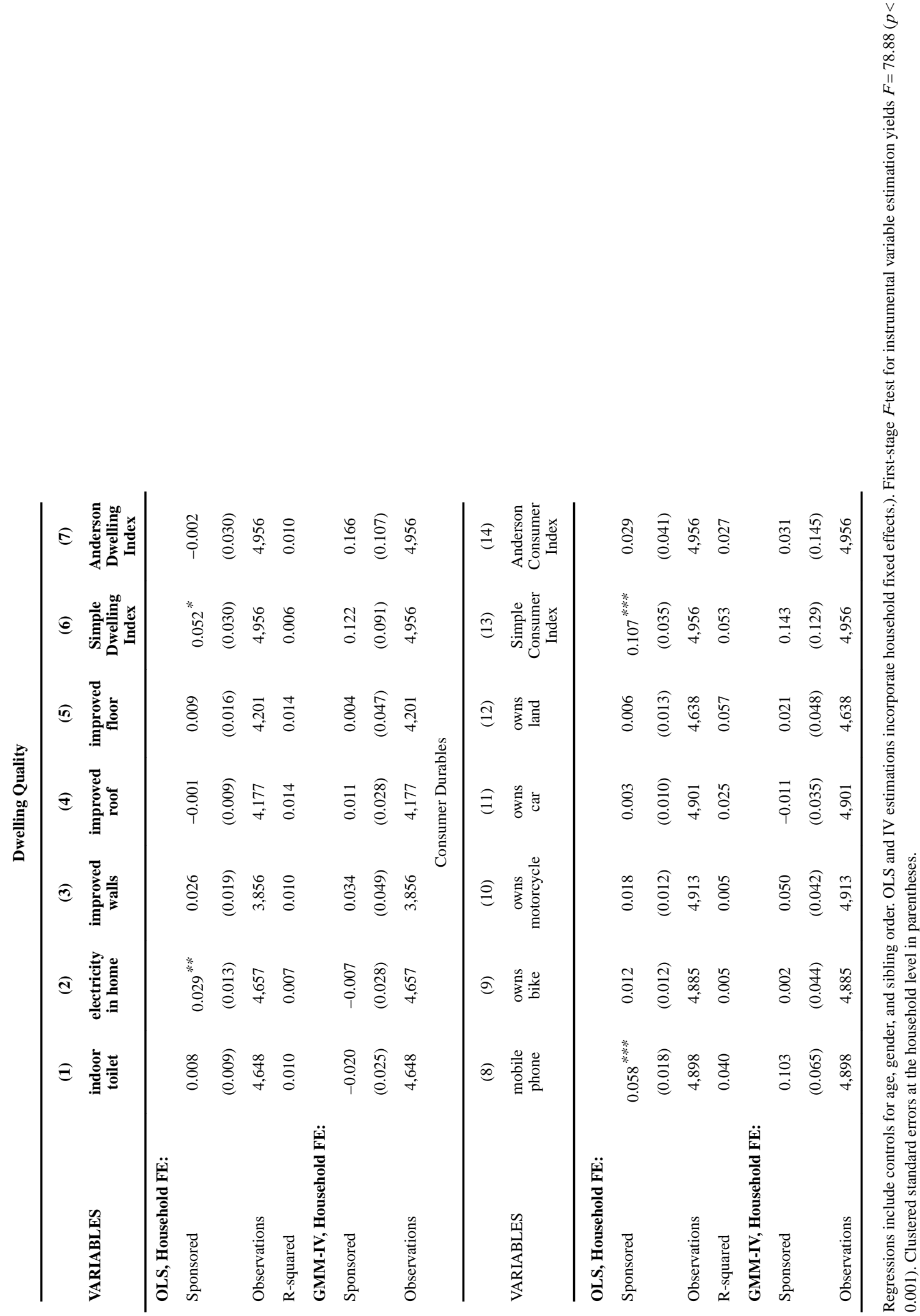




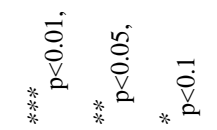

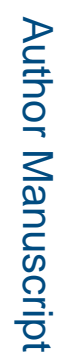

로을

를

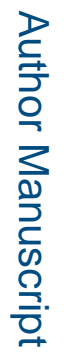

World Bank Econ Rev. Author manuscript; available in PMC 2018 June 20. 


\section{를 \\ 공}

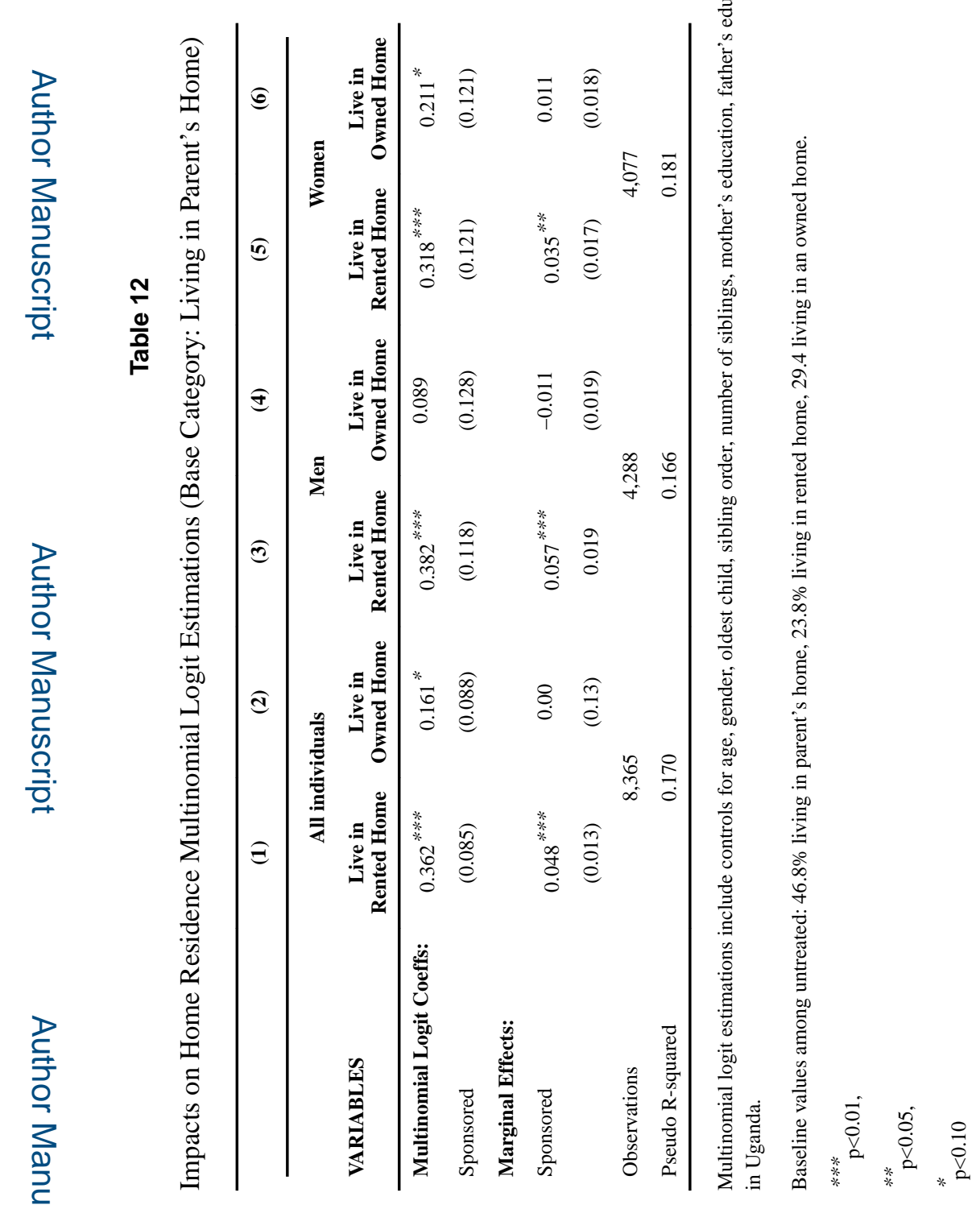

World Bank Econ Rev. Author manuscript; available in PMC 2018 June 20. 